Revista lus et Praxis, Año 18, No 2, 2012, pp. 147 - 188

ISSN 0717 - 2877

Universidad de Talca - Facultad de Ciencias Jurídicas y Sociales

"El testimonio de las partes en juicio propio.

Análisis histórico comparativo a partir de las experiencias de Inglaterra y Austria"

Ramón García Odgers

\title{
EL TESTIMONIO DE LAS PARTES EN JUICIO PROPIO. ANÁLISIS HISTÓRICO COMPARATIVO A PARTIR DE LAS EXPERIENCIAS DE INGLATERRA Y AUSTRIA*
}

Ramón García Odgers ${ }^{* *}$

\begin{abstract}
RESUMEN
El sujeto mejor informado de los hechos deducidos en el juicio es normalmente la parte misma, sin embargo, por el interés personal que tiene en los resultados del caso, también puede ser la prueba menos confiable. La disyuntiva de los sistemas de justicia es utilizar o no esa valiosa información. La reforma al proceso civil chileno, en materia de utilización de ese saber, ha sido puesta en el debate, ya que el Proyecto de Nuevo Código Procesal Civil contempla, en forma expresa, la posibilidad de que las partes declaren libremente en su propio juicio. Este trabajo presenta una perspectiva favorable a la reforma en este punto, a partir de un análisis histórico que confronta la realidad procesal chilena con dos experiencias relevantes del derecho comparado. Se demostrará que la tendencia histórica, orientada a proporcionar una mayor racionalidad a los sistemas probatorios, es favorable a este instituto.

El desarrollo de la libertad probatoria, la oralidad, una mayor confianza hacia el juzgador y la eliminación de prejuicios abstractos y formalistas, constituyen los hilos conductores de este proceso.
\end{abstract}

ABSTRACT

The parties are the better informed of the facts deduced at trial, but at the same time, for the personal interest they have in the outcome of the case, Imay also be the less reliable evidence. The dilemma of the judicial systems is to use or not that valuable information. The Chilean civil process reform, in the use of this knowledge has been put into the debate. This paper presents a favorable outlook for this reform, from a historical analysis of the party witness rule evolution. With regard to the existing regulation on this subject in our procedures, we will analyze two relevant experiences of comparative law. It will be shown that this evolution, is inserted in a global historical trend that began several centuries ago, aimed at providing a more rational evidentiary systems to ensure a better determination of the facts.

The development of free proof, orality, greater confidence in the

\footnotetext{
* El autor agradece las valiosas sugerencias y correcciones que sobre este trabajo que hicieran los Profesores, Drs. Álvaro Pérez Ragone y Leonardo Raznovich. Trabajo recibido el 24 de septiembre y aprobado el 3 de octubre de 2012.

** Profesor de Derecho Procesal y Litigación, Facultad de Derecho de la Universidad Católica de la Santísima Concepción. Cursa Segundo año del Programa de Doctorado de la Pontificia Universidad Católica de Valparaíso. Correo electrónico: rgarcia@ucsc.cl.
} 
adjudicator body, and the abstract and formal prejudices
elimination, are the threads of this process.

Palabras Clave

Partes, Testigos, Prueba

KEYWORDS

Parties, Witnesses, Evidence

\section{INTRODUCCIÓN}

El sujeto mejor informado de los hechos deducidos en el juicio es normalmente la parte misma. En efecto, son muchos los hechos de los cuales la parte puede ser la mejor, o incluso, la única fuente de prueba. Sin embargo, por el interés personal que tiene en los resultados del caso, la parte también puede ser la prueba menos confiable.

La disyuntiva de los sistemas de justicia es utilizar o no esa valiosa información. La reforma al proceso civil chileno, en materia de utilización de ese saber, ha sido puesta en el debate'.

Como se expondrá, nuestra tradición procesal, fuertemente enraizada en el sistema de prueba legal y transmitida de forma acrítica por varias generaciones, ha prescindido de aquella información. Aun cuando un cierto cuestionamiento se manifestó a partir de las reformas de familia y laboral que establecieron oralidad, libertad de prueba y su valoración libre y, por ende, principios contrarios a nuestro actual procedimiento civil, en general, el peso de esta herencia se ha impuesto ${ }^{2}$. Con todo, la controversia se ha promovido, fundamentalmente por los operadores jurídicos, a nivel de interpretación lege data, precisamente porque la regulación normativa de los aspectos probatorios en los procesos de familia y laboral deja espacios para cierta discusión. Sorprende, dada la importancia de esta materia para la configuración de un sistema de procesos por audiencias, que la doctrina nacional no le haya prestado mayor atención, y que sólo se conozca de una investigación que trata del testimonio de la parte con autonomía temática ${ }^{3}$.

La finalidad de este trabajo, es aportar a un debate que se muestra particularmente relevante en la actualidad, a propósito de la incorporación de la decla-

\footnotetext{
${ }^{1}$ Cfr. artículo 331 del Proyecto de Nuevo Código Procesal Civil. Versión disponible en el sitio web del Ministerio de Justicia de Chile www.minjusticia.gob.cl, revisada por última vez el 15 de marzo de 2012.

${ }^{2}$ Cfr. Fuentes, Claudio, "La persistencia de la prueba legal en la judicatura de Familia", Revista de Derecho de la Universidad Católica del Norte No 1, Vol. 18, 2011, pp. 119 a 145.

${ }^{3}$ Marín Verdugo, Felipe, "Declaración de Parte como Testigo", Revista lus et Praxis № 1, Vol. 16, 2010, pp. 125-170.
} 
ración libre de las partes en juicio propio en el Proyecto de reforma al proceso civil. Este cambio requiere una justificación teórica que permita su correcto entendimiento y compatibilización con los principios del sistema considerados en conjunto. El debate, en consecuencia, requiere ser reconducido a esquemas teóricos más amplios a fin de encontrar explicaciones y generar soluciones que nos permitan contar con un sistema de justicia coherente.

Teniendo presente que el tema es de una amplitud mayor, me propongo en esta investigación revisar acotadamente dos experiencias relevantes del derecho comparado. Se trata, si se prefiere, de una exploración, especialmente en aquellas jurisdicciones donde la transición, desde la prohibición del testimonio pro se, hacia su consagración general se ha materializado, identificando factores y elementos que pueden contribuir a un mejor entendimiento de las diversas aristas que este tema envuelve.

La experiencia disponible en el derecho comparado sobre la evolución del testimonio de las partes y de personas interesadas en el resultado del juicio, resulta particularmente relevante y clarificadora no sólo para identificar y comprender la justificación teórica de este instituto, sino también para el entendimiento contextual de las reformas procesales y las culturas que tras ellas van desapareciendo, cediendo paso a otras con paradigmas radicalmente diversas ${ }^{4}$.

Para estos propósitos, he seleccionado los ejemplos de Inglaterra y Austria. El caso de Inglaterra es paradigmático, ya que fue en esta jurisdicción que, bajo la influencia de prominentes juristas, se inició el ataque conceptual más consistente contra las reglas abstractas y absolutas de exclusión de evidencias, cuestionando directamente la racionalidad de la regla que excluía el testimonio de las partes y de testigos interesados. El caso de Austria se nos presentó como muy relevante, ya que fue la primera jurisdicción continental en abolir la regla que consideraba a las partes inhabilitadas para testificar bajo juramento, y cuyo ejemplo fue visto como una solución prudente y de transición por otros países de Europa.

En la primera parte de este trabajo se expondrá una breve relación histórica del tratamiento de uso del saber de la parte en nuestro sistema procesal civil, para luego, conectar el tema con el vigoroso proceso de reformas a la justicia que ha impuesto un cambio de paradigma respecto de los procedimientos y la prueba. En este punto se destacará la diferencia de tratamientos normativos y prácticos que, en materia de declaración de parte, es posible identificar en los distintos sistemas reformados. Finalizaremos con una acotada descripción de la importancia de una declaración libre de las partes en la configuración de un sistema oral.

${ }^{4}$ Para un estudio acabado del tema, véase CAPPELLetTI, Mauro, El testimonio de la parte en el sistema de la oralidad. Contribución a la Teoría de la utilización probatoria del saber de las partes en el proceso civil, Tomos I y II, Traducción de Banzhaf, Thomas A., Librería Editora Platense, La Plata, 2002. 
En la segunda parte, se presentará la evolución del testimonio de la parte en juicio propio en Inglaterra. Se describirá, en primer lugar, la configuración de la regla de common law que prohibía la declaración de la parte y de otros testigos interesados en el resultado del juicio, adquiriendo en este sistema jurídico -gracias al instituto del jurado- la categoría de reglas de exclusión. A continuación, se revisarán los principales hitos que marcaron el decaimiento y posterior eliminación de las reglas que impedían testificar tanto a las partes como a testigos interesados en el resultado del juicio. Nos enfocaremos en el debate que promovieron prominentes juristas de la Inglaterra del siglo XIX contra el sistema vigente de reglas de evidencia, y que constituyeron el paso previo a sucesivas modificaciones legislativas, tanto en los procesos civiles como criminales.

Una tercera parte se centra en la evolución del instituto de la declaración de parte como testigo en Austria. Destacaremos la influencia de juristas destacados en el ataque a la rigidez del juramento, y su propuesta de establecer la declaración libre de la parte, su materialización en diversos cuerpos legales y la influencia que la configuración de este instituto en la Ordenanza Procesal Civil de 1895 generó en otros países de la tradición continental.

Al finalizar presentaremos algunas conclusiones que sintetizan los resultados de nuestra investigación.

\section{El testimonio de LA PARTE EN JUICIO PROPIO: \\ UNA DESCRIPCIÓN DEL ACTUAL SISTEMA PROCESAL CHILENO, SU RELACIÓN CON LAS REFORMAS A LA JUSTICIA Y EL SISTEMA DE LA ORALIDAD}

Es notable que el testimonio de la parte y de testigos interesados, como medios de pruebas válidos y útiles, fuera tempranamente justificado en nuestro país en el siglo XIX por Andrés Bello.

En efecto, en carta publicada en 1835 en El Araucano, sobre Administración de Justicia, planteó que la regla debía ser la amplia admisibilidad del testimonio, incluso del testigo interesado, con la finalidad de asegurar la averiguación de los hechos 5 . Frente a la posibilidad de recurrir al testimonio de las partes mismas, se mostró derechamente partidario de su utilización, pero sometiéndolo a diversos controles, tales como el contrainterrogatorio, la presencia del Juez, de la parte contraria, y del público ${ }^{6}$. En otra carta de 1837, Bello se declaraba

\footnotetext{
${ }^{5}$ Betlo, Andrés, Obras Completas de don Andrés Bello, Opúsculos Jurídicos, volumen IX, edición hecha bajo la dirección del Consejo de Instrucción Pública en cumplimiento de la lei de 5 de septiembre de 1872, Santiago, Impreso por Pedro G. Ramírez, 1881-1883, p. 84.

${ }^{6}$ En la referida carta se expresaba textualmente: “QQueremos oír a la parte? Arranquémosle la verdad toda entera; descartemos por el interrogatorio cruzado todos los subterfujios, todas las falsedades que pueda sujerirle el interés; $i$ haciendo el exámen a presencia del juez, de la parte contraria, i de aquel
} 
seguidor, en materias de prueba, de Bentham, valorando la confesión de parte como la prueba más natural, pero agregando que su defecto radicaba en el modo de recibirla, básicamente por su formato escrito y la mediación de escribano ${ }^{7}$. Sobre el juramento, Bello se mostró escéptico, ya que este mecanismo se basa en la fuerza del sentido religioso del que lo presta ${ }^{8}$. Finalmente, en cuanto a la testimonial, y luego de enumerar las causales de inhabilidad de los testigos, criticaba su exclusión anticipada por entorpecer la verdad ${ }^{9}$, planteando que el único espíritu de dichas leyes era liberar al juez del trabajo de indagación sobre la capacidad y buena fe de los testigos, y que, muchas de ellas, eran contrarias al sentido común y generaban injusticias ${ }^{10}$. Por ello, planteaba reemplazar el esquema por uno sin exclusiones de testigos, y con una valoración entregada al Juez ${ }^{11}$.

No obstante estos auspiciosos inicios, nuestro sistema probatorio acabó configurándose de un modo muy diferente.

a) La declaración de parte en el sistema procesal civil chileno.

Una descripción histórica de su regulación

Por cierto, el proceso civil, instaurado por el Código de Procedimiento Civil del año 1902, no significó un cambio sustancial en cuanto a la forma de impartir justicia en el ámbito civil, al modelo que de facto funcionaba en Chile desde los tiempos de la colonia ${ }^{12}$. De acuerdo a ello, subsistió un procedimiento ordinario según el modelo castellano con algunas especialidades indianas, lo que implicó la vigencia de las Partidas (en especial la Tercera), y a las normas pertenecientes a la Novísima Recopilación ${ }^{13}$, caracterizado por su rigurosa escrituración ${ }^{14}$. En consonancia con lo anterior, las reglas sobre prueba, éstas terminaron por configurar un sistema probatorio con características predominantes de prueba

incorruptible guardador de los derechos privados, el público, arredrémosle de apelar al perjurio". Bello, Andrés, Obras, cit. nota n. 5, p. 85.

${ }^{7}$ Bello, Andrés, Obras, cit. nota n. 5, p. 223.

${ }^{8}$ Bello, Andrés, Obras, cit. nota n. 5, p. 225.

${ }^{9}$ Bello, Andrés, Obras, cit. nota n. 5, p. 229.

${ }^{10}$ Betlo, Andrés, Obras, cit. nota n. 5, p. 229.

${ }^{11}$ Bello, Andrés, Obras, cit. nota n. 5, p. 232.

12 Núñez, Raúl, "Crónica sobre la Reforma del Sistema Procesal Civil Chileno (Fundamento, Historia y principios)", en Proceso Civil, Hacia una Nueva Justicia Civil, De la Oliva, Andrés y Palomo, Diego (Coordinadores), Editorial Jurídica de Chile, Santiago, 2007, p. 677.

${ }^{13}$ Montero Aroca, Juan, La herencia procesal, Universidad Autónoma de México, México, 1994, p. 7.

${ }^{14}$ Palomo Vélez, Diego, "Las Marcas del Proceso Oral y Escrito diseñado en el Proyecto de Nuevo CPC Chileno", Revista Chilena de Derecho No 3 Vol. 36, 2009, p. 626. 
legal ${ }^{15}$, regulándose tanto en el Código Civil de $1855^{16}$, como en Código de Procedimiento Civil de $1902^{17}$.

En efecto, desde una perspectiva histórica jurídica, estas normas corresponden al período de la codificación, esto es, a una etapa en que el derecho común deja de tener vigor en cuanto forma y al mismo tiempo se aprovecha en cuanto materia ${ }^{18}$. Así, la prueba legal de los códigos se basó en una técnica mucho más simple que las distinciones analíticas y complicadas que, entre tipos y subtipos, los juristas del derecho común trataron de racionalizar la diversidad de los casos concretos $^{19}$. A pesar de ser más simple, fue al mismo tiempo más rígida y formalista, fundándose en generalizaciones de supuestas máximas de experiencia y estableciendo pruebas que decidían automáticamente la litis sin relación alguna con la situación probatoria global que se produce en el caso concreto $^{20}$.

Los primeros proyectos de Código Civil y el de 1853, no contenían disposiciones sobre las pruebas ${ }^{21}$, apareciendo recién en la primera revisión del Proyecto de 1853, Ilamado Proyecto Inédito ${ }^{22}$, regulándose la confesión de parte y el juramento deferido (actual 1698 del Código Civil) ${ }^{23}$, como únicos medios que permiten directamente la utilización de la información de la parte, lo que resulta consistente con las fuentes que se utilizaron ${ }^{24}$. Por otro lado, la doctrina de la época, en general, era muy escéptica de la prueba de testigos, conside-

\footnotetext{
${ }^{15}$ Cfr. Palomo Vélez, Diego, "La Prueba en el Proceso Civil Chileno. ¿Una actividad asumida con suficiente seriedad?" en Proceso Civil, Hacia una Nueva Justicia Civil, De la Olıva, Andrés y Palomo, Diego (Coordinadores), Editorial Jurídica de Chile, Santiago, 2007, pp. 353 a 363.

${ }^{16}$ Cfr. Código Civil de Chile, Título XXI del Libro IV, artículos 1698 a 1714, y Código de Procedimiento Civil, Libro II, Títulos IX, X y XI, artículos 318 a 429.

17 Marín Verdugo, Felipe, Declaración, cit. nota n. 3, p. 140.

${ }^{18}$ Guzmán Brito, Alejandro, La Codificación Civil en Iberoamérica, Siglos XIX y XX, Editorial Jurídica de Chile, Santiago, 2000, p. 23.

${ }^{19}$ TARUfFo, Michele, La prueba de los hechos, Traducción de Beltrán, Jordi, Editorial Trotta S.A, Madrid, 2005, p. 392.

${ }^{20}$ TARuffo, Michele, La prueba, cit. nota n. 19. p. 392.

${ }^{21}$ Claro Solar sostiene que Bello estimaba que esta materia correspondía más bien al derecho procesal, y que podían seguir aplicándose los principios de la legislación romana sancionadas en las leyes de la Partida tercera y algunas recopiladas que reglamentaban las pruebas judiciales. Cfr. Claro Solar, Luis, Explicaciones de derecho civil y comparado, Editorial Nascimento, Santiago, 1939, Tomo 12, p. 658.

22 Bello, Andrés, Obras Completas. Tomo Quinto. Proyecto de Código Civil (Santiago, 1932), III, pp. 445 a 449 .

${ }^{23}$ Bello, Andrés, Obras Completas. Tomo Quinto, cit. nota n. 22, p. 445.

${ }^{24}$ Cfr. García Goyena, Florencio, Concordancias, Motivos y Comentarios del Código Civil Español, Editorial Cometa S.A., Zaragoza, 1974, pp. 634 y 635.
} 
rándola una fuente de corrupción de las costumbres y ejemplo de sobornos, lo que justificó que las Ordenanzas de Moulins de 1566, la excluyera para todos los contratos que excedieran de 100 libras $^{25}$, definición que, en términos muy similares, fue seguida por los códigos civiles de la época ${ }^{26}$.

Aun cuando, el Código Civil entregó la regulación del juramento a las disposiciones del futuro Código de Enjuiciamiento ${ }^{27}$, éste finalmente no fue incorporado en su catalogo de medios de prueba ${ }^{28}$, ni en otros textos legales, salvo un resabio consignado en el Código de Comercio de $1865^{29}$. Por otro lado, la confesión de parte, fue incorporada en el Código Civil en un solo artículo $^{30}$, estableciendo que producía plena prueba contra el declarante, con la excepción de los actos y contratos que requieren de instrumento público ${ }^{31}$. Esta norma, debe correlacionarse con los artículos 385 a 402 del Código de Procedimiento Civil, que, básicamente, disponen la oportunidad y forma que ella debe rendirse, por medio de posiciones escritas y rígidas ${ }^{32}$, similares a la interrogatio per positiones del proceso canónico y común ${ }^{33}$. En general, la doctrina nacional no ha manifestado un reproche concreto sobre este sistema de absolución de posiciones, limitándose a sistematizar las normas respectivas o citar la jurisprudencia disponible ${ }^{34}$.

Con todo, en este contexto procesal es posible advertir algunas manifestaciones de utilización de la información que poseen las partes con fines probatorios. Así, en materia comercial, los asientos de los libros del comerciante ${ }^{35}$,

${ }^{25}$ Pothier, Robert Joseph, Tratado de las Obligaciones, Parte Primera, Traducido por una sociedad de amigos colaboradores, Barcelona, 1839, p. 486.

${ }^{26}$ Cfr. Verlanga Huerta, F. y Muñiz Miranda, J., Concordancias entre el Código Civil Francés y los Códigos Civiles Estrangeros, $2^{\text {a }}$ edición, Madrid, 1847.

${ }^{27}$ Cfr. artículo 1714 del Código Civil.

${ }^{28}$ Cfr. artículo 341 del Código de Procedimiento Civil.

${ }^{29}$ Cfr. artículo 37 del Código de Comercio.

${ }^{30}$ Esta norma corresponde al artículo 1882 "o", del Proyecto Inédito en el cual no aparecen fuentes de referencia. Bello, Andrés, Obras Completas. Tomo Quinto. Cit. nota n. 22, p. 448.

${ }^{31}$ Cfr. artículo 1713 del Código Civil de Chile.

${ }^{32}$ Cfr. artículos 385 a 402 del Código de Procedimiento Civil de Chile.

${ }^{33}$ Sobre el sistema de posiciones Cfr. Palacios, Joaquín, Instituciones del Derecho Civil de Castilla, que escribieron los doctores Aso y Manuel, Tomo II, $7^{\text {a }}$ edición, Madrid, 1806, pp. 261 y ss.

${ }^{34}$ Cfr. Rioseco Enríquez, Emilio, La Prueba ante la Jurisprudencia. Derecho Civil y Procesal Civil. Confesión de Parte, $1^{\text {a }}$ edición, Editorial Jurídica de Chile, Santiago, 1998; Rodríguez Papic, Ignacio, Procedimiento Civil. Juicio Ordinario de Mayor Cuantía, $5^{a}$ edición, Editorial Jurídica de Chile, Santiago, 1995, pp. 165 y ss., y Benavente Gorroño, Darío, Derecho Procesal Civil. Juicio Ordinario y Recursos Procesales, $5^{\text {a }}$ edición, Editorial Jurídica de Chile, Santiago, 2004, pp. 71 y ss.

${ }^{35}$ Cfr. artículo 39 del Código de Comercio. 
en materia procesal civil, la confesión calificada no es divisible en perjuicio del confesante ${ }^{36}, y$, la prueba de las acciones civiles en el juicio penal, por aplicación de las reglas del Código Procesal Penal ${ }^{37}$.

\section{b) Las reformas al sistema procesal. Nuevos paradigmas antiguas lógicas}

En las últimas décadas se ha observado un inédito proceso de transformación de los sistemas judiciales ${ }^{38}$, el que también ha alcanzado a nuestro continente ${ }^{39}$. Mirado el fenómeno desde el punto de vista de los procedimientos, las reformas han tenido como denominador común el cambio hacia sistemas en que se privilegia la oralidad ${ }^{40}$, herramienta que asegura la vigencia de otros principios que se estiman fundamentales en la configuración del debido proceso ${ }^{41}$, al hacer operativas las garantías del juicio público, la inmediación, la contradicción, y el plazo razonable ${ }^{42}$.

\footnotetext{
${ }^{36}$ Cfr. Artículo 401 del Código de Procedimiento Civil.

${ }^{37}$ Cfr. Artículo 324 del Código Procesal Penal.

${ }^{38}$ LANGer, Máximo, "Revolution in Latin América Criminal Procedure: Diffusion of legal ideas from the periphery", American Journal of Comparative Law, Vol. 55, 2007, p. 618. Para las reformas procesales de Inglaterra y Estados Unidos, véase MARCus, Richard L., "Putting American procedural exceptionalism into a globalized context", The American Journal of Comparative Law, Vol. 53, 2005, pp. 709-740.

${ }^{39}$ Una perspectiva comparada del proceso de reformas en Latinoamérica puede encontrarse en el Proyecto de Seguimiento de Reformas a la Justicia del Centro de Justicia de las Américas (CEJA), disponible en www.cejAméricas.org.

${ }^{40}$ Una lectura de estos principios y su vinculación con la oralidad desde una perspectiva continental comparada, véase en Perez Ragone, Alvaro-PAlomo, Diego, "Oralidad y prueba: Comparación y análisis crítico de las experiencias reformadoras del proceso civil en Alemania y España", Revista de Derecho Pontificia Universidad Católica de Valparaíso № XXXII, Vol. 1, 2009, pp. 363-406 Una revisión sobre los alcances de la implementación de la oralidad y su relación con la eficiencia procesal puede encontrase en CARPI, Federico-Ortells Ramos, Manuel (editores), Oralidad y escritura en un proceso civil eficiente. Oral and Written Proceedings: Efficiency in Civil Procedure, Tomos I y II, $1^{\text {a }}$ edición, Universitat de Valencia, Valencia, 2008. Cfr. CAPPELletTI, Mauro, La oralidad y las pruebas en el proceso civil, $1^{a}$ edición, Ediciones Jurídicas Europa-América S.A, Buenos Aires, 1972.

${ }^{41}$ Un ejemplo de esta afirmación se encuentra en el Mensaje del proyecto de ley que crea los Tribunales de Familia. Historia de la Ley 19.968 que crea los Tribunales de Familia. Disponible en el sitio web de la Biblioteca del Congreso Nacional: www.bcn.cl.

${ }^{42}$ Cfr. Preámbulo: XIV Cumbre Judicial IberoAmerican a desarrollada en Brasilia, 2008, pp. 2 y 3. Disponible en http://www.cumbrejudicial.org/c/document_library/get_file?uuid=8b98e368-a52a444e-8766-73c28c2690f7\&groupld=10124. Sitio visitado por última vez el 9 de marzo de 2012. También el Informe Final del Foro Procesal Civil, p. 9, disponible en el sitio web del Ministerio de Justicia de Chile:http://rpc.minjusticia.gob.cl/es/estudios-y-documentos/file/178-informe-procesal-civilforo?start=5, sitio visitado por última vez el 24 de mayo de 2012.
} 
Un sistema de procesos por audiencias combina la oralidad con la escrituración para la toma de decisiones relevantes del proceso. Ello implica, en lo medular, un contacto inmediato y personal del juez con las partes y sus pruebas, tendiente a la generación de un escenario que favorezca una correcta calificación jurídica de los hechos. Se trata, entonces, de asegurar que la información que se genere en ellas sea de alta calidad, dada la inmediación y la percepción directa de la evidencia por el juez, y el contexto de contradicción e interacción que supone. La oralidad, en consecuencia, se relaciona básicamente con la prueba de los hechos del proceso, como lo demuestra Cappelletti al descartar su utilidad en las etapas de proposición de la demanda y de argumentación ${ }^{43}$.

Por ello, para hacer del juicio oral una herramienta eficaz y consistente en los términos enunciados, se requiere -como condición necesaria- que las reglas sobre prueba tengan un diseño que le sea consistente ${ }^{44}$. En este sentido, la gran mayoría de las reformas procedimentales implementadas en el último tiempo, han abandonado el sistema de prueba legal, consagrando la libertad probatoria y la valoración de los medios probatorios con apego a las reglas de la sana crítica ${ }^{45}$.

Sin embargo, los sistemas reformados de familia y laboral, regulan la declaración de parte manteniendo, en lo sustancial, el esquema de la confesión judicial bajo el formato de absolución de posiciones ${ }^{46}$ herencia del sistema de prueba legal del proceso común romano canónico, según lo cual sólo se permite la declaración de la parte que es solicitada por iniciativa de la contraria, lo que además supone-según su configuración procedimental- obtener y valorar sólo aquella información que le perjudica ${ }^{47}$.

En las escasas fuentes doctrinarias disponibles sobre estos procesos reformados no se observa una preocupación sobre el tema de la declaración de parte,

\footnotetext{
${ }^{43}$ Cfr. Cappellettı, Mauro, La oralidad, cit. nota n. 40, pp. 87 y 88.

${ }^{44}$ Duce, Mauricio; Marín, Felipe; Riego, Cristián, "Reformas a los Procesos Civiles Orales: Consideraciones desde el debido proceso y la calidad de la información", en Justicia Civil: Perspectiva para una reforma en América Latina, CABEZÓN, Andrea (Coordinadora), Centro de Estudios de Justicia de las Américas, Santiago, 2008, p. 47.

${ }^{45}$ Cfr. Caroca, Álex, "Recuperación de la Importancia de la Prueba en un Modelo Procesal Civil Oral", en Proceso Civil, Hacia una Nueva Justicia Civil, en De la Oliva, Andrés y Palomo Vélez, Diego (Coordinadores), (Editorial Jurídica de Chile, Santiago, 2007, pp. 365 y ss.

${ }^{46}$ Ver el artículo 50 de la Ley № 19.968 sobre Tribunales de Familia y los artículos 454 números 3 y 4 del Código del Trabajo.

${ }^{47}$ Sobre las inconsistencia entre las reglas de prueba y la oralidad, véase DuCE, Mauricio; MaRíN, Felipe; RiEGO, Cristián, Reformas, cit. nota n. 44, pp. 48 y ss.
} 
que incluya la hipótesis su declaración voluntaria en juicio propio ${ }^{48}$, salvo una excepción que la propone lege ferenda en materias de familia ${ }^{49}$.

En síntesis, en un contexto de oralidad, inmediación y libertad de prueba, la configuración normativa y práctica judicial han mantenido vigente el principio nullus idoneus testis in re sua intellegitur, nemo testis in re sua auditur, y nemo in propia causa testis debet, esto es, que a nadie se le considera testigo idóneo en causa propia, sin que aparezca suficientemente justificado a nivel normativo las razones que autorizan la exclusión de la información pertinente que las partes poseen y que le favorece.

Si el rasgo que define al juicio de admisibilidad de las pruebas en un contexto judicial es su sello jurídico, y, en consecuencia, el juez debe ofrecer razones amparadas en el ordenamiento vigente para romper con la regla básica de libertad de medios ${ }^{50}$, la operatoria de esta clase de exclusión es injustificada.

En este escenario, algo difuso, se abre paso la reforma al proceso civil, la que busca superar los paradigmas que constituían la estructura del Código de Procedimiento Civil de 1902. Fuertes críticas a su excesiva escrituración, desconcentración, delegación de funciones, distanciamiento entre el juez y los justiciables, lentitud se han levantado por la doctrina nacional más moderna, reclamando por la incorporación de principios radicalmente distintos ${ }^{51}$.

El Proyecto de Nuevo Código Procesal Civil contempla en forma expresa la posibilidad de que las partes puedan declarar voluntariamente, ante el tribunal que conoce del asunto, y en la audiencia de juicio, para lo cual, deben solicitarlo en los escritos principales del período de discusión. Dicha declaración

\footnotetext{
${ }^{48}$ En el proceso de Familia, Cfr. Baeza, Gloria, y Pérez, Jaime, Los Nuevos Tribunales de Familia, Procedimiento Ordinario. $2^{\mathrm{a}}$ edición, Legal Publishing, Santiago, 2008, pp. 122 y 123. También. López Díaz, Carlos, Manual de Derecho de Familia y Tribunales de Familia, Tomo II, $1^{\text {a }}$ edición, Librotecnia, Santiago, 2005), p. 715 a 716; SILva, Rodrigo, Manual de Tribunales de Familia, $1^{\text {a }}$ edición, Editorial Jurídica Colección de Manuales Jurídicos, Santiago, 2005, p. 78 y ss.; y, Correa Selamé, Jorge, Derecho Procesal de Familia, $1^{\text {a }}$ edición, Thomson Reuters Punto Lex, Santiago, 2009, pp. 79 y ss. En materia del proceso laboral Cfr. CANDiA Guzmán, Claudio y KoCH Cid, Karla, Reforma Procesal del Trabajo, 2 ${ }^{\text {a }}$ edición, Editorial Metropolitana, Santiago, 2009, pp. 114 y ss., y Fernández Toledo, Raúl, Las Facultades y Deberes del Juez en materia Probatoria en el Proceso Laboral. Análisis Crítico, $1^{\text {a }}$ edición, Thomson Reuter Punto Lex, Santiago, 2011, pp. 234 y ss. y 354 y ss.

${ }^{49}$ Alcaíno Torres, Rodrigo y Cortés De La Cerda, Matías, Curso Elemental de Litigación Oral, $1^{\text {a }}$ edición, Editorial Jurídica de Chile Colección Manuales Jurídicos, Santiago, 2012, pp. 178 y 179.

${ }^{50}$ Larroucau Torres, Jorge, "Por un estándar amplio de admisibilidad de pruebas en la justicia civil", en Libro Homenaje al Centenario de la Facultad de Derecho de la Universidad de Valparaíso, Edeval, Valparaíso, 2012, p. 9.

${ }^{51}$ Entre otros, Cfr. NúÑez, Raúl, Crónica, cit. nota n. 12, pp. 677 y ss.; Palomo Vélez, Diego. Las Marcas, cit. nota n. 14, pp. 621 a 661; e Informe Final del Foro Procesal Civil, disponible en el sitio web del Ministerio de Justicia de Chile:http://rpc.minjusticia.gob.cl/es/estudios-y-documentos/file/178-informeprocesal-civil-foro?start=5, visitado por última vez el 24 de mayo de 2012.
} 
será prestada personalmente y bajo juramento o promesa de decir verdad. La contraparte tendrá derecho a dirigirle preguntas y contrainterrogaciones. En caso de existir pluralidad de partes activas o pasivas, el tribunal podrá restringir este derecho cuando estime que de sus declaraciones pueda resultar una reiteración inútil sobre los mismos hechos o circunstancias ${ }^{52}$.

Esta proposición constituye una apuesta por incorporar el máximo de información al juicio, y es consistente con un estándar de admisibilidad amplio, y cláusulas de libertad de prueba y valoración racional. Por otro lado, de convertirse en ley, se dará un paso adelante en la consolidación de un sistema procesal que, en su conjunto, sea coherente con los principios que proclama.

\section{LAS PARTES COMO TESTIGOS, \\ UNA LECTURA FAVORABLE DESDE LA PERSPECTIVA CONTINENTAL. \\ SU IMPORTANCIA COMO FUENTE DE INFORMACIÓN Y SU RELACIÓN CON LA ORALIDAD}

Mauro Cappelletti afirmó que no puede haber una efectiva realización de la concepción de la oralidad en un proceso en el cual no se haya valorizado plenamente el interrogatorio libre de la parte, entendido como un examen o coloquio de las partes ante el juez sobre hechos de la causa, del cual el juez pueda sacar elementos para formar su propio libre convencimiento sobre la verdad de esos hechos ${ }^{53}$. Este contacto juez-partes llevará a la inmediación precisamente allí donde es más viva la necesidad de esa inmediación, o sea respecto de los hechos que nadie conoce tanto como las partes mismas ${ }^{54}$.

La eliminación de las reglas que determinan la imposibilidad de que una parte testifique en su favor en juicio propio presenta un impacto revolucionario sin igual, ya que, las partes habrán sido de regla los protagonistas más directos de esos hechos y, por ende, sus testigos más calificados, aun cuando no hay que descuidar tampoco la valoración del interés de cada parte y el consiguiente peligro de una deformación consciente e inconsciente de los hechos ${ }^{55}$.

Esta antigua forma de exclusión - de las partes como testigos-, controvertida y desaparecida el siglo XIX de los sistemas civiles del common law, está corriendo la misma suerte en los sistemas continentales.

\footnotetext{
${ }^{52}$ Cfr. artículo 331 del Proyecto de Nuevo Código Procesal Civil. Versión disponible en el sitio web del Ministerio de Justicia de Chile www.minjusticia.gob.cl, revisada por última vez el 15 de marzo de 2012.

${ }^{53}$ Cappelletti, Mauro, El testimonio de la parte en el sistema de la oralidad. Contribución a la Teoría de la utilización probatoria del saber de las partes en el proceso civil, Tomo I, Traducción de Banzhaf, Thomas A., Librería Editora Platense, La Plata, 2002, p. 14.

${ }^{54}$ Cappelletti, Mauro, El testimonio, cit. nota n. 53, p. 45.

${ }^{55}$ Cappelletti, Mauro, El testimonio, cit. nota n. 53, pp. 45 y 46.
} 
Jolowicz señala que es un principio general de los países continentales que las partes en litigación no son testigos competentes, aun cuando pueden ser interrogados por el Juez por iniciativa propia. Este interrogatorio originalmente tuvo sólo el propósito de clarificación de la demanda o de la contestación, sin embargo, ahora es común que el Juez pueda examinar a las partes sobre los hechos del caso $^{56}$. En el mismo sentido, destacados autores todavía plantean que la declaración de partes es uno de los principales elementos diferenciadores del procedimiento civil de ambos sistemas. Así, Cappalli plantea que este es un tema que diferencia claramente el proceso civil chileno con el de Estados Unidos $^{57}$. Damaska consigna que en los procesos civiles del sistema continental existe bastante renuencia a utilizar a las partes como fuentes de pruebas, y frecuentemente sólo se llaman a testificar como último recurso cuando no bastan otras pruebas para dictar el veredicto ${ }^{58}$.

Con todo, un importante sector de la doctrina procesal continental está de acuerdo con el uso del conocimiento de la parte con fines probatorios en calidad de testigos. Se ha dicho que ello es de lógica elemental, sin que se justifique efectuar distinciones según se trate de proceso penal, civil o de otra índole ${ }^{59}$. Se ha señalado también que en todos los procesos debe autorizarse el libre interrogatorio de las partes, introducido ya en el proceso civil de algunos países, por su indiscutible eficacia ${ }^{60}$. Un análisis crítico del modelo de prueba argentino describe que las partes no pueden ser testigos en su causa, y que esta, entre otras prohibiciones, generan el efecto de excluir prueba pertinente, y tornan a la prueba testifical en algo secundario ${ }^{61}$.

\footnotetext{
${ }^{56}$ Jolowicz, J.A., On Civil Procedure, 1ª edición, Cambridge University Press, London, 2000, p. 215.

${ }^{77}$ Cfr. Cappallu, Richard, "Procedimiento Civil Comparado: Estados Unidos, Chile y Sudamérica", Revista Chilena de Derecho, Pontificia Universidad Católica de Chile № 2, Vol. 19, 1992, pp. 439 a 441 .

${ }^{58}$ Damaska, Mirjan R., The Faces of Justice and the State Authority. A Comparative Approach of the Legal Process, $1^{\text {a }}$ edición, Yale University Press, Yale, 1986, pp. 126 y ss.

${ }^{59}$ De Santo, Víctor, La Prueba Judicial. Teoría y Práctica, $1^{\text {a }}$ edición, Editorial Universidad, Buenos Aires, 1992, pp. 229 y 230.

60 "COL 202, 207 y 208; BRA 344 y 414 y ss.; MEX 317; URU, 437; VEN, 296. Ceñidos al rigorismo formal que exige la presentación previa del pliego escrito conteniendo las posiciones están los códigos de ARG (NAC, 410; BUE, 408; CBA, 220, SFE, 160); BOL, 415; COS, 251; CHI, 387; ECU, 124; GUA, 131; PER, 366; URU, 437; ESP, 581". Devis EChandía, Hernando, Compendio de la Prueba Judicial, Tomo I, Anotado y Concordado por Adolfo Alvarado Velloso, Rubinzal-Culzoni, Buenos Aires, 2000, I, p. 250. En contra, Cfr. GorpHe, François, La crítica del testimonio, $6^{a}$ edición, traducción española de la segunda edición francesa de Mariano Ruiz-Funes, REUS, Madrid, 2003, pp. 134 a 137.

${ }^{61}$ RAZNOVICH, Leonardo, "Los principios generales del derecho probatorio y el proceso civil", Revista IberoAmerican a de derecho procesal, Vol. 9, 2006, pp. 202 y 203.
} 
Para Bentham las partes mismas interesadas en la causa podían declarar también en calidad de testigos ${ }^{62}$. Por su lado, en la doctrina continental, la declaración de las partes como un verdadero testimonio recibiría una fuerte acogida, ya en Carnelutti. ${ }^{63}$ En efecto, tanto el testigo como la parte, representan personal y mediatamente hechos históricos y la peculiar modalidad bajo la cual se verificaron, sin que en este punto quepa ninguna distinción por su fuente entre el hecho narrado o descripto por uno y por otro. El hecho testimoniado en este aspecto puede ser lógicamente idéntico en un caso y en el otro ${ }^{64}$. Otro autor plantea que es corriente hablar de testimonio de parte, en sentido amplio, y de confesión únicamente cuando de tal testimonio se deducen hechos desfavorables para el declarante ${ }^{65}$.

A nivel normativo, un ejemplo de avance, es el caso español, el que, a propósito de la reforma a su proceso civil, admitió de algún modo la posibilidad de interrogación a la parte, pero siempre provocada por la parte contraria ${ }^{66}$. En este mismo sentido, las reglas UNIDROIT/ALI, que contienen una serie de principios que pretenden alcanzar una armonización entre los sistemas procesales del common law y del civil law para la litigación comercial adopta en la regla 16 el testimonio de las partes libremente valorado ${ }^{67}$.

El panorama descrito en esta sección, resulta auspicioso para la aceptación de la declaración libre de la parte con fines probatorios. En efecto, por una parte, nos encontramos en medio de un proceso de ruptura con las lógicas de la prueba legal, y sus criterios de exclusión apriorísticos. Las reformas procesales, por

${ }^{62}$ Bentham, Jeremy, A Treatise on Judicial Evidence, Messrs, Baldwin, Cradock, and Joy, PaternosterRow, London, 1825, p. 88.

${ }^{63}$ Carnelutti, Francesco, La Prueba Civil, $2^{a}$ edición, traducción castellana de N. Alcalá-Zamora, Arayu, Buenos Aires, 1955, pp. 147 a 151.

${ }^{64}$ Kielmanovich, Jorge, Medios de Prueba, $1^{\text {a }}$ edición, Abeledo Perrot, Buenos Aires, 1993, p. 32.

65 Devis Echandía, Hernando, Compendio de la Prueba Judicial, Compendio de la Prueba Judicial, Tomo II, Anotado y Concordado por Adolfo Alvarado Velloso, $1^{\text {a }}$ edición, Rubinzal-Culzoni, Buenos Aires, 2000, p. 16.

${ }^{66}$ El inciso primero del artículo 306 de la Ley de Enjuiciamiento Española referente al interrogatorio de partes dispone que "Art. 306. Facultades del tribunal e intervención de abogados. Interrogatorio cruzado.- 1. Una vez respondidas las preguntas formuladas por el abogado de quien solicitó la prueba, los abogados de las demás partes y el de aquella que declarare podrán, por este orden, formular al declarante nuevas preguntas que reputen conducentes para determinar los hechos. El tribunal deberá repeler las preguntas que sean impertinentes o inútiles". Texto extraído de la versión electrónica disponible en el sitio http://www.boe.es/aeboe/consultas/enlaces/documentos/leyes_procesales/ley_enjuiciamiento_civil.pdf, visitado por última vez el 20 de mayo de 2012.

${ }^{67}$ El principio 16.1 acuerda que el testimonio de la parte tendrá potencialmente el mismo peso que el de cualquier otro testigo, aun cuando la Corte evaluando dicha evidencia pueda tomar en cuenta el interés de la parte en la disputa. Disponible en http://www.unidroit.org/english/principles/civilprocedure/ ali-unidroitprinciples-e.pdf, revisado por última vez el 29 de marzo de 2012. 
otro, han incorporado reglas amplias de libertad probatoria y su valoración en sana crítica, en los cuales la justificación de reglas de exclusión de este tipo de información carece de sustento intrínseco. Por otro lado, un importante sector de la doctrina también se muestra proclive a la aceptación de la interrogación libre de las partes como testigos. Finalmente, en contextos normativos cercanos al nuestro como el español, y tendencias unificadoras como las reglas Unidroit/ Ali, también podemos constatar manifestaciones concretas de la aceptación del testimonio libre de las partes.

En las líneas que siguen, nos abocaremos a destacar los hitos históricos, tanto de la transición, como de la esfera en que se desarrolló el debate para la aceptación del testimonio de las partes en juicio propio en Inglaterra y Austria.

\section{La DECLARACIÓN DE PARTE Y LOS TESTIGOS INTERESADOS. \\ DE LA EXCLUSIÓN A LA HABILIDAD Y CAPACIDAD.}

EL CASO DE INGLATERRA

En Inglaterra, antes de las leyes reformadoras de la llamada Acta de Lord Denman, la utilización del saber de las partes quedaba excluida más radicalmente de lo que lo estaba, en aquel tiempo, en los ordenamientos continentales ${ }^{68}$. McCormick, señala que, por lejos, la regla de common law más drástica sobre capacidad o competencia fue la doctrina que excluía el testimonio de las partes en el juicio y de todas las personas con interés propietario o pecuniario directo en los resultados del juicio. Esta regla impuso tanto la inhabilidad sobre las partes para testificar en su favor como el privilegio de no ser llamado como testigo contra él mismo por su adversario ${ }^{69}$. Estaba excluida, incluso el instituto del juramento deferido a la parte por el adversario o por el juez y entendido como instrumento para la decisión de las litis ${ }^{70}$.

Por otro lado, si bien existía en las Courts of Equity, una especie de interrogatorio al que una parte podía someter al adversario ${ }^{71}$, se trataba de un instituto absolutamente formal, ya sea por la estructura -las preguntas se sometían por la parte al adversario por escrito, y daban lugar a una contestación igualmente escrita y firmada por el defensor, y jurada-, sea por los efectos, dirigido a pro-

\footnotetext{
${ }^{68}$ Cappelletti, Mauro, El testimonio de la parte en el sistema de la oralidad. Contribución a la Teoría de la utilización probatoria del saber de las partes en el proceso civil, Tomo II , Traducción de Banzhaf, Thomas A., Librería Editora Platense, La Plata, 2002, p. 7.

${ }^{69}$ Broun, Kenneth S., McCormick On Evidence, 6 a edición, Thomson West, United States of America, 2006, p. 119.

${ }^{70}$ CappellettI, Mauro, El testimonio, cit. nota n. 68, p. 7.

${ }^{71}$ Clermont, Kevin M., Principles of Civil Procedure, $2^{\text {a }}$ edición, Thompson West, Minessota, 2009, p. 22.
} 
mover la confesión del adversario ${ }^{72}$. En consecuencia, este interrogatorio de las Courts of Equity era un instituto derivado y hasta copiado del proceso canónico y precisamente de aquel interrogatorio per positiones, que es el antepasado de nuestro interrogatorio formal como también de los españoles interrogatorios de posiciones así como del francés interrogatoire sur faits et articles ${ }^{73}$.

No obstante, a diferencia del sistema continental, el sistema de prueba legal con sus abstracciones apriorísticas no fue tan penetrante al sistema probatorio de las Courts of Common Law inglesas, por el instituto del jurado ${ }^{74}$. No solamente este instituto imponía un método procesal oral y, por consiguiente, el contacto directo e inmediato entre juez y jurado de un lado y fuentes de prueba, en particular los testigos, del otro lado, sino que esta oralidad e inmediación hicieron también menos fácil la penetración de reglas de valoración numérica y abstracta de las pruebas. A ello se oponía, más que ninguna otra cosa, el propio buen sentido y el espíritu de independencia de los jueces populares que reivindicaban su libertad en el juicio de los hechos a ellos confiados ${ }^{75}$.

\section{a) La configuración de la regla de exclusión de common law}

En las Cortes inglesas de Common Law, el sistema de la prueba legal se manifestó bajo la forma de reglas limitadoras de la admisión de ciertas pruebas. Una vez admitida y asumida la prueba era difícil sustraerla del buen sentido e independencia de los jurados. Más fácil era, en cambio, prescribir apriorísticamente toda una serie de reglas de exclusión y de descalificaciones, o sea de inadmisibilidades: por ejemplo, la inadmisibilidad del testimonio de la parte o de los terceros interesados ${ }^{76}$.

En todo caso, la exclusión del testimonio de las partes y de aquellos interesados en el resultado del juicio, fue una regla tradicional de common law. La descalificación por intereses, sea cual sea su origen, no es peculiar del sistema de jurado, ya que se encuentra bien establecido, mediante la adopción del derecho romano, en las reglas eclesiásticas como se practica en Inglaterra ${ }^{77}$.

\footnotetext{
72 Cappelletti, Mauro, El testimonio, cit. nota n. 68, p. 8.

${ }^{73}$ Cappelletti, Mauro, El testimonio, cit. nota n. 68, p. 9.

${ }^{74}$ Cappelletti, Mauro, El testimonio, cit. nota n. 68, p. 7.

${ }^{75}$ Cappelletti, Mauro, El Proceso Civil en el Derecho Comparado. Las Grandes Tendencias Evolutivas, $1^{a}$ edición, traducción de Santiago Sentis Melendo, Ediciones Jurídicas Europa-América S.A., Buenos Aires, 1972, p. 96.

${ }^{76}$ Cappelletti, Mauro, El Proceso Civil, cit. nota n. 75, p. 97.

77 Wigmore, John Henry, A Treatise on the Anglo-American of Evidence in Trials at Common Law including the and Judicial Decisions of All Jurisdictions of the States and Canada, 2 ${ }^{\mathrm{a}}$ edición, Little, Brown, and Co., Boston, 1923, p. 989.
} 
Se señala que la teoría de la descalificación por interés no fue más que una variedad la teoría general que subyace en las extensas reglas de incompetencia del common law ${ }^{78}$. Esta era, en esencia, reducible a un silogismo, ambas premisas, que hoy día nos podrían parecer suficientemente falaces, pero que en los 1700 fueron aceptadas como axiomas de verdad: La total exclusión es la salvaguardia contra la decisión falsa, siempre que las personas ofrecidas son de una clase especialmente inclinadas a decir falsedades; Personas que tienen un interés pecuniario en la causa son especialmente proclives a decir falsedades; por tanto, tales personas deben ser totalmente excluidas ${ }^{79}$.

Estas exclusiones fueron adoptadas tempranamente por las cortes, determinando que un testigo interesado era probablemente falso, y, por tanto, no debía ser oído. Esta forma de preclusión fue aplicada a las partes civiles, a los acusados criminalmente y a los testigos interesados ${ }^{80}$. En efecto, en el siglo XVII, la descalificación de las partes se había enraizado en la idea de que las personas con intereses en los resultados del juicio podrían no ser de confianza para decir la verdad, entonces esta exclusión fue necesaria para prevenir a estos en caer en perjurio y proteger a la Corte de la decepción. Basado en esta razón, la regla fue extendida en la mitad del siglo diecisiete para descalificar a testigos terceros interesados ${ }^{81}$. Se menciona, como ejemplo de extensión de esta regla, el caso de un informante que recibía una recompensa si el acusado era condenado y, por tanto, tenía un interés en el resultado que lo hacía incompetente para testificar ${ }^{82}$.

Se atribuye al final del siglo XVI la primera articulación de la regla que impide el testimonio jurado de las partes en una acción civil, trazando su origen en la competición entre el jurado y el viejo procedimiento de wager of law ${ }^{83}$. En el procedimiento de wager of law, el acusado se defendía a sí mismo y si elegía este método, le era permitido hacer una declaración ante el tribunal, bajo juramento que esta declaración era verdadera, y presentando uno o más individuos que juraban que ellos creían que lo que aquel había dicho bajo juramento era verdad. Esta fue la forma predominante de defensa en las Cortes Feudales y persistió por un tiempo en las Cortes del common

\footnotetext{
${ }^{78}$ Wigmore, John Henry, A Treatise, cit. nota n. 77, p. 996.

${ }^{79}$ Wigmore, John Henry, A Treatise, cit. nota n. 77, p. 996.

${ }^{80}$ Colquitt, Joseph A. y Gamble, Charles W., "From Incompetency to weight and credibility: The next step in an historic trend", Alabama Law Review, Vol. 47, 1995, p. 147.

${ }^{81}$ Wigmore, John Henry, A Treatise, cit. nota n. 77, p. 999.

${ }^{82}$ Oldham, James, "Informal Lawmaking in England by the Twelve Judges in the Late Eighteenth and Early Nineteenth Centuries", Law and History Review No 1, Vol. 29, 2011, p. 215.

${ }^{83}$ Wigmore, John Henry, A Treatise, cit. nota n. 77, p. 996.
} 
$\operatorname{law}^{84}$. Similares argumento fueron recogidos en el fallo de la Corte Suprema de USA, en el caso Ferguson v State of Georgia de $1961^{85}$.

La extensión de la regla de exclusión del testimonio para acusados penalmente llegó ligeramente más tarde. En los procesos penales, el acusado tenía la necesidad de tomar una parte activa de su defensa, desde que inicialmente tanto su derecho a abogado ${ }^{86}$ como su derecho a llamar testigos en su nombre estuvieron severamente restringidos ${ }^{87}$. Langbein señala que recién fue entre 1734 y 1735, que el abogado defensor comenzó a ser permitido que examinara y contaexaminara testigos ${ }^{88}$. El acusado no fue juramentado, ni tampoco, hasta el comienzo del siglo dieciocho, lo fueron ninguno de sus testigos. Sólo con los estatutos de 1695 y 1701, que permitieron a los testigos del acusado ser juramentados en casos de traición y felonía, se distinguió entre el rol del testimonio del acusado y de los testigos ordinarios traídos al juicio: el acusado podía hablar pero no bajo juramento. Esta diferencia fue explicada en términos del interés del acusado en los resultados del juicio ${ }^{89}$.

Durante el siglo XVIII y el comienzo del XIX, la regla de common law sobre exclusión por interés disfrutó un largo e incuestionable predominio. Como señala Oldham en la práctica de las cortes Inglesas del siglo dieciocho, dos mecanismos pensados para establecer la verdad fueron el requisito del juramento y la "regla de la parte testigo", a través del cual las partes litigantes fueron consideradas demasiado interesadas en el asunto discutido para ser confiable para testificar ${ }^{90}$. En el common law se siguió simplemente la experiencia común de la humanidad de ese tiempo ${ }^{91}$. Las partes de un litigio civil fueron incompetentes para declarar por temor al perjurio. Las objeciones a los

\footnotetext{
${ }^{84}$ Cfr. Hamowy, Ronald, "F.A. Hayek and the common law", Cato Journal № 2, Vol. 23, 2003, pp. 246 a 248.

${ }^{85}$ Cfr. 365 U.S. 570, 81 S.Ct. 756.

${ }^{86}$ Lancbein, John H., "The Prosecutorial Origins of Defence Counsel in The Eighteenth Century: The Appearance of Solicitors", Cambridge Law Journal № 2, Vol. 58, July 1999, p. 314.

${ }^{87}$ Langbein, John H., "The Privilege and Common Law Criminal Procedure: The Sixteenth to the Eighteenth Centuries", en The Privilege against Self-Incrimination. Its Origins and Developments, HelmHolz, R. H. (ed.), University of Chicago Press, Chicago, 1997, p. 82.

${ }^{88}$ Lancben, John, "The Criminal Trial Before the Lawyers", The University of Chicago Law Review, Vol. 45, 1978, p. 312.

${ }^{89}$ BODANSKY, Joel N, "The abolition of party witness disqualification: An historical survey", Kentucky Law Journal, Vol. 70, 1981, p. 92.

${ }^{90}$ Oldham, James, "Truth-Telling in the Eighteenth-Century English Courtroom", Law and History Review № 1, Vol. 12, 1994, p. 96.

${ }^{91}$ Aвraham, Kenneth, "The Common Law Prohibition on Party Testimony and the Development of Tort Liability", Virginia Law Review, № 3, Vol. 95, 2009, p. 492.
} 
testigos sobre la base de interés figuraban prominentemente en las notas civiles del Juez Dudley Ryder ${ }^{92}$.

La descalificación de las partes para testificar reforzó poderosamente la preferencia del common law por la prueba escrita, especialmente en materia de contratos. Como las partes no podían testificar sobre sus transacciones, esto debió haber alentado, a quienes eran más prudentes a planificar y canalizar sus asuntos importantes por escrito ${ }^{93}$. Sin embargo, al menos en algunos casos, fue posible obtener una solicitud de discovery en los procedimientos in equity, que permitía compeler a la otra parte a dar testimonio, la que sería entonces jurídicamente admisible ${ }^{94}$. Así, antes de las reformas, en Inglaterra la situación de la declaración de las partes en el proceso de las Cortes de common law, era mixta.

En efecto, el instituto del jurado había desplegado su influencia, por un lado, en el sentido que la prueba testimonial no pudiese asumir aquel carácter, escrito y formal, que tenía en cambio en el proceso de las Courts of Equity, donde el juez se limitaba a tomar vista de las actas extendidas por los examiners o por los commissioners, cuando la prueba debía practicarse a más de veinte millas de Londres ${ }^{95}$. Por otro lado, y a causa de una cierta desconfianza en la experiencia y capacidad de discernimiento de los jurados, se sustraía de su apreciación el saber de las partes, salvo la admisión espontáneamente rendida, y el de los terceros que tuvieran aunque fuese un mínimo de interés económico en el caso ${ }^{96}$. En cambio, en el proceso de las Courts of Equity, por la mayor confianza en el juez togado y por la influencia, además, del sistema procesal canónico, se admitía aquí un interrogatorio de las partes con fines probatorios, pero con estructura y efectos rígidamente formales y unilaterales, esto es, la mera posibilidad de provocar una confesión de la parte interrogada, pero no un testimonio libremente valorable ${ }^{97}$. La misma prueba testimonial tenía un carácter sustancialmente escrito y formal; de ahí los gravísimos y generalmente reconocidos y combatidos inconvenientes del proceso in equity, que aun bajo un cierto perfil, o sea con referencia a la posibilidad de utilizar aunque imperfectamente el saber de las partes, se manifestó superior al de las Cortes de common law, y tanto es así que precisamente esta superioridad

\footnotetext{
${ }^{92}$ Langbein, John H., "Historical foundations of the law of evidence: A view from the Ryder sources", Columbia Law Review No 5, Vol. 96, 1996, p. 1184.

93 LanGBeIN, John H., "Historical...", cit. nota n. 92, p. 1185.

${ }^{94}$ Abraham, Kenneth, The Common Law Prohibition, cit. nota n. 91, p. 494.

${ }^{95}$ Cappellettı, Mauro, El Testimonio, cit. nota n. 68, p. 12.

${ }^{96}$ Cappelletti, Mauro, El Testimonio, cit. nota n. 68, pp. 12 y 13.

${ }^{97}$ Cappelletti, Mauro, El Testimonio, cit. nota n. 68, p. 13.
} 
fue, en los siglos pasados, la causa de la consolidación de una parte de la jurisdicción in equity ${ }^{98}$.

b) El inicio de los cambios. La creciente consolidación de la configuración adversarial del proceso en las Cortes del common law

Hacia el final de la edad media, el jurado sufrió una profunda transformación de un rol de activo investigador a uno pasivo. En efecto, en un principio el sistema medieval de jurados era de auto información, en el cual difícilmente tuvo un lugar para un derecho de la prueba ${ }^{99}$. En una época de pequeñas comunidades agrícolas intensamente interdependientes, los jurados fueron seleccionados del vecindario de los hechos debatidos. La esperanza era que un jurado de la localidad contendría testigos, personas que conocerían los hechos, o si no, que estos jurados estarían bien posicionados para investigar los hechos por sus medios ${ }^{100}$. Aun cuando investigaciones históricas recientes sugieren, sin embargo, que los jurados no siempre estuvieron en posición para conocer los hechos que había ocurrido ${ }^{101}$, lo cierto es, que los jurados fueron libres de utilizar el conocimiento privado adquirido fuera de la Corte ${ }^{102}$. El jurado medieval fue a la Corte no a escuchar sino a hablar, no a oír evidencia sino a entregar un veredicto formulado por adelantado. La Corte aceptaba este rudo veredicto, sin preocuparse de investigar los procesos lógicos, si lógicos eran, del cual el veredicto era su resultado ${ }^{103}$.

Menos de un siglo y medio después se estableció que el jurado debía basar su veredicto, no sobre su conocimiento personal, sino que solamente sobre la evidencia entregada en la Corte. El juicio por Jurados había sido transformado en un procedimiento adversarial ${ }^{104}$. Se señala que algunos de los atributos más fundamentales del proceso penal moderno Anglo Americano emergió en Inglaterra durante el siglo XVIII: el derecho probatorio, el sistema adversarial,

\footnotetext{
${ }^{98}$ Cappelletti, Mauro, El Testimonio, cit. nota n. 68, pp. 13 y 14.

${ }^{99}$ Nokes, G.D., "The English Jury and the Law of Evidence", Tulane Law Review, Vol. 31, 1956-1957, p. 154.

${ }^{100}$ Cfr. LangBeIN, John H., "The Disappearance of Civil Trial in the United States", Yale Law Journal 2012, p. 9.

101 Otson, Trisha, "The Passing of the Ordeals and the Rise of the Jury Trial", Syracuse Law Review, Vol. 109, 2000, p. 21.

${ }^{102}$ Landsman, Stephan, "The Rise Of The Contentious Spirit: Adversary Procedure In Eighteenth Century England", Cornell Law Review, Vol. 75, 1989-1990, p. 499.

${ }^{103}$ LanGbein, John H., Historical foundations, cit. nota n. 92, p. 1170.

${ }^{104}$ Morgan, Edmund M., "The Jury And The Exclusionary Rules Of Evidence", The University of Chicago Law Review, № 2, Vol. 4, 1937, pp. 247 y ss.
} 
el privilegio contra la autoincriminación, y, las principales reglas sobre la relación entre el juez y el jurado ${ }^{105}$. En efecto, ya para el siglo XVII, el jurado se comenzó a parecer al panel que se reconoce en la práctica moderna: un grupo de ciudadanos ya no más elegidos por su conocimiento de los hechos, sino más bien elegidos en la expectativa que serían ignorantes de ellos. La declinación del jurado auto informado fue fundamental. El jurado perdió el monopolio de la información ${ }^{106}$.

Por otro lado, se apunta que los autores de principios del siglo XIX, vinieron a ver la litigación en un contexto fundamentalmente adversarial. Los participantes en el proceso adjudicatorio fueron asignados generalmente en lo que hoy día sería considerado roles adversariales ${ }^{107}$.

El uso de información extrajudicial no fue más enfatizado. La interrogación de los testigos por las partes se convirtió en la forma por la cual el jurado era informado. ${ }^{108}$ Esta interrogación fue el núcleo del procedimiento en la sala de la Corte y la base de la sentencia. Restricciones categóricas y nociones numéricas fueron abandonadas en su mayor parte como guías de la decisión. La preferencia por los escritos se erosionó, la insistencia por formalidades tales como el juramento disminuyeron en importancia, y la exclusión de los testigos fue reducida ${ }^{109}$. Tanto en casos criminales como civiles, los abogados se transformaron en críticos participantes de la entrega de la evidencia. Ellos, más que los jueces, guiaron la interrogación. Interferencias de la Corte en la interrogación fue criticada ${ }^{110}$.

Este jurado pasivo requirió un procedimiento de instrucción de la Corte por medio del cual los testigos extraños le entregaran información, las instrucciones al jurado del juicio hicieron posible el derecho de la evidencia ${ }^{111}$. El juez desarrolló un poder para advertir el mérito de la evidencia, lo que fue bien recibido por el jurado ${ }^{112}$. Una vez que los testigos rutinariamente testificaran en una audiencia pública, el monopolio práctico de los jurados fue frenado, ya

\footnotetext{
${ }^{105}$ LangBeIN, John H., "Shaping the Eighteenth-Century Criminal Trial: A View from the Ryder Sources", The University of Chicago Law Review No 1, Vol. 50, 1983, p. 2.

${ }^{106}$ LANGBeIn, John H., Judges and Judging in the History of Common Law and Civil Law: From antiquity to modern time, BRAND, Paul (Editor), Cambridge University Press, London, 2012, p. 76.

107 Landsman, Stephan, "From Gilbert To Bentham: The Reconceptualization Of Evidence Theory", Wayne Law Review, Vol. 36, 1989-1990, p. 1172.

108 LaNDSMAN, Stephan, "From Gilbert...", cit. nota n. 107, p. 1172.

${ }^{109}$ Landsman, Stephan, "From Gilbert...", cit. nota n. 107, p. 1172.

${ }^{110}$ LANDSMAN, Stephan, "From Gilbert...", cit. nota n. 107, p. 1172.

111 LangBein, John, Historical foundations, cit. nota n. 92, p. 1171.

112 LangBein, John, Judges and Judging, cit. nota n. 106, p. 77.
} 
que el juez del juicio escuchó el mismo testimonio que el jurado, el fue capaz de comentar sobre la evidencia y asesorar al jurado sobre cómo aplicar la ley, y regular el testimonio de los testigos en el juicio ${ }^{113}$.

Se ha afirmado que nadie se dedicó a construir el sistema adversarial. No era ni parte de un gran plan gubernamental ni el esquema de un ingenioso filósofo legal. Los jueces, abogados y litigantes del siglo XVIII en Inglaterra se ocupaban de sus asuntos sin saber que eran los instrumentos de un histórico "propósito" o que el producto de su trabajo sería un nuevo sistema de adjudicación ${ }^{114}$. En este contexto, Inglaterra fue la primera jurisdicción que removió la regla de exclusión que impedía a las partes testificar.

\section{c) La Reforma: Un proceso gradual. El rol de la Doctrina}

Un primer intento destinado a circunscribir el alcance de la regla de exclusión, se hizo desde 1833 por el Act for the Further Amendment of the Law and the Better Advancement of Justice ${ }^{115}$. Pero este Estatuto, que sustancialmente tendía solamente a hacer menos frecuente la falta de admisión del testimonio de los terceros por razones de interés, fue pronto superado por el Lord Denman's Act de 22 de agosto de 1843, el cual abolía completamente la descalificación de las personas interesadas, aun manteniendo firme, en cambio, la prohibición de la deposición rendida por la parte misma o por el cónyuge de la parte $^{116}$.

La competencia para testificar de las partes civiles fue reconocida en 1851 por conducto de la Lord Brougham's Act ${ }^{17}$, y para los acusados criminalmente en 1898 por la Criminal Evidence Act ${ }^{118}$. Finalmente, en 1869, el Evidence Further Amendment Act, hizo admisible el testimonio de las partes también en las causas por promesa violada de matrimonio, con la expresa disposición, sin embargo, que dicho testimonio, en cuanto rendido por el actor en prueba

\footnotetext{
${ }^{113}$ LANGBEIN, John, Historical foundations, cit. nota n. 92, p. 1171.

${ }^{114}$ Landsman, Stephan, The Rise Of The Contentious Spirit, cit. nota n. 102, p. 502.

${ }^{115}$ Cfr. Eardiey-Wilmot, John E., Lord Brougham Law's Reform, Longman, Brown, Green, Longman and Roberts, London, 1860, pp. 213 y ss.

${ }^{116}$ Eardiey-Wilmot, John E., Lord Brougham Law's Reform, cit. nota n. 115, p. 215. También Cfr. PowelL, Edmund, The Principles and Practice of the Law, $3^{\mathrm{a}}$ edición, Hodges, Foster and Co; London, 1869, p. 34, y Wigmore, John Henry, A Treatise, cit. nota n. 77, p. 1002.

${ }^{117}$ Eardley-Wilmot, John E., Lord Brougham Law’s Reform, cit. nota n. 117, p. 215. También Powell, Edmund, The principles and practice of the law, cit. nota n. 116, p. 25.

${ }^{118}$ Para una descripción de la evolución histórica de las leyes inglesas que eliminaron la incompetencia para testificar en materias criminales, Cfr. KeANe, Adrian, The Modern Law of Evidence, $7^{a}$ edición, Oxford University Press, Gran Bretaña, 2008, pp. 120 y ss.
} 
de la promesa de matrimonio, no debía considerarse prueba por sí suficiente, sino que debía ser corroborada por otra prueba, y permitiendo, además, el testimonio, ya sea de las partes o de sus cónyuges, en las causas relativas a adulterio, dejando firme el derecho tanto de las partes como de los terceros, de no responder a demandas dirigidas a demostrar que el sujeto interrogado es culpable de adulterio ${ }^{119}$.

El derecho probatorio moderno, centrado en el testimonio oral, suplantó al antiguo, abandonando el esfuerzo de tratar el documento en forma preferente, y la regla de la mejor evidencia (best evidence) como principio organizador del derecho de la evidencia ${ }^{120}$. El contra examen reemplazó el juramento como salvaguardia para la recepción de la prueba oral, derribando el régimen de competencia que había descalificado a las partes por interés, y permitiendo que la regla del hearsay asumiera ese último carácter ${ }^{121}$.

En suma, el sistema basado en el juramento presuponía el temor del testigo de que Dios condenaría el perjurio. En lugar de la anterior confianza en la venganza de Dios, el nuevo orden sustituyó esta fe, por la detección de la verdad en la eficacia de los contrainterrogatorios de los abogados ${ }^{122}$.

El método adversarial fue creado por jueces y abogados que buscaron, a través de cientos de reformas incrementales, construir un sistema más equitativo en la Corte $^{123}$. Se ha dicho que el nacimiento y afianzamiento de la cultura adversarial puede ser explicado por dos factores: la amplia profesionalización de la justicia penal, y el cambio radical en la ideología política y social que ocurrió durante la Ilustración ${ }^{124}$.

La doctrina fue fundamental en el ataque contra la descalificación por interés. Se destacan, especialmente Jeremy Bentham, Thomas Denman, y Henry Brougham ${ }^{125}$, estos últimos, admiradores y seguidores de Bentham y que desde sus altos cargos en la magistratura británica, ejercitaron una influencia directa sobre las reformas legislativas ${ }^{126}$.

${ }^{119}$ Cappelletti, Mauro, El testimonio, cit. nota n. 68, pp., 22 y 23.

${ }^{120}$ LangBeIN, John H., Historical foundations, cit. nota n. 92, p. 1194.

${ }^{121}$ LangBeIN, John H., Historical foundations, cit. nota n. 92, p. 1194.

122 Langbein, John H., Historical foundations, cit. nota n. 92, p. 1200.

${ }^{123}$ Landsman, Stephan, The Rise Of The Contentious, cit. nota n. 102, p. 604.

${ }^{124} \mathrm{~S}_{\mathrm{MITH}}$, Tom, "Zealous Advocates: The Historical Foundations of the Adversarial Criminal Defence Lawyer", Law, Crime And History, 2012. Disponible en Solon Online Journal, Http://Www.Pbs.Plymouth.Ac.Uk/Solon/Hjournal2012vol1.Html, visitado por última vez el 14 de julio de 2012.

${ }^{125}$ Wigmore, John Henry, A Treatise, cit. nota n. 77, p. 1002.

${ }^{126}$ Goodhart, Arthur L., "A Changing Approach to the Law of Evidence", Virginia Law Review N ${ }^{\circ} 5$, Vol. 51, 1965, pp. 773. 
Se señala que la idea de que las partes, y más en general los "sujetos interesados", no deberían, con abstracto apriorismo formal, excluirse del número de las personas susceptibles de contribuir a la formación de la libre convicción (de los jurados) del juez, es uno de los temas centrales, más fecundos y más originales de la doctrina de Bentham en materia de pruebas ${ }^{127}$. Detrás de los argumentos particulares, es frecuente la idea que el intelecto humano es capaz de manejar información sobre los hechos sin restricciones: bien fundados y razonando en sana lógica, la capacidad intelectual de las personas puede proveer una suficiente garantía de que decisiones correctas pueden ser alcanzadas ${ }^{128}$.

El argumento central de los reformadores fue que la exclusión del testimonio dificultaba el gran objeto de la investigación judicial, "el descubrimiento de la verdad"129. La exclusión, prohibía la producción de evidencia que podía ser crítica para una decisión correcta ${ }^{130}$. En este sentido, el planteamiento general de Bentham era que "la prueba es la base de la justicia: excluir pruebas es excluir verdad"131. Las reglas de descalificación de los testigos con conocimientos sobre los hechos relevantes del caso constituyen un obstáculo para el esclarecimiento de la verdad ${ }^{132}$. Este reclamo abolicionista ha permeado el discurso legal por aproximadamente dos siglos ${ }^{133}$. Bentham entendía que, en particular, la exclusión de un testimonio por interés, era considerada como una garantía en contra del error a que este testimonio podía llevar. Sin embargo, esta desconfianza la estimaba excesivamente peligrosa ${ }^{134}$.

En efecto, los reformadores percibieron que la exclusión por interés descansaba en dos supuestos que rechazaban: primero, que el interés en el resultado del juicio los llevaría a cometer perjurio, y segundo, que el perjurio, si era intentado, no sería detectado por quienes determinan los hechos ${ }^{135}$. Sobre la primera premisa Bentham replicó que rechazar como indigno de crédito la evidencia de un hombre que tiene cualquier interés pecuniario en la causa, incluso el más insignificante, es una injuriosa y degradante desconfianza, que supone que los hombres son peores de lo que son, de acuerdo con el promedio usual de

\footnotetext{
${ }^{127}$ Cappelletti, Mauro, El Testimonio, cit. nota n. 68, p. 5.

${ }^{128}$ NiJBoer, J.F., "Common Law Tradition In Evidence Scholarship Observed From A Continental Perspective", The American Journal of Comparative Law, Vol. 41, 1993, p. 32.

${ }^{129}$ Bodansky, Joel N., The abolition, cit. nota n. 89, p. 94.

${ }^{130}$ Landsman, Stephan, From Gilbert To Bentham, cit. nota n. 107, p. 1177.

131 Bentham, Jeremy, Rationale of Judicial Evidence, Tomo IV (Hunt and Clarke, London, 1827, 4, p. 490.

132 Broun, Kenneth S., McCormick On Evidence, cit. nota n. 69, p. 126.

${ }^{133}$ StEIn, Alex, Foundations of Evidence Law, Oxford University Press, New York, 2008, p. 108.

134 Bentham, Jeremy, A Treatise, cit. nota n. 62, p. 247.

135 BoDAnSky, Joel N., The abolition, cit. nota n. 89, p. 94.
} 
moralidad $^{136}$. Otros también criticaron la exclusión, señalando que no tan solo fallaba para distinguir entre grados de interés y diferencias de carácter, sino que también fallaban en considerar a aquellos que, incluso si lo intentaban, serían persuadidos de no cometer perjurio, tanto por la sanción del juramento o por el miedo a ser detectados ${ }^{137}$. También señalaron que era ilógico excluir el testimonio sólo por ser indigno de crédito, y lo mejor era permitir y dejar la determinación de ello a quienes les correspondía la determinación de los hechos ${ }^{138}$.

La regla de exclusión también fue atacada por inconsistente, pues con ella se impedía sólo el testimonio de aquellos que tenían un interés pecuniario en el caso, pero permitía que se ofreciera como testigos, a aquellos que tenían un igual o mayor interés en el caso, como los parientes, amigos, y enemigos ${ }^{139}$.

Los reformistas no desestimaron el riesgo del perjurio; más aún, ellos argumentaron que la exclusión exageraba el peligro que la falsedad escaparía de la detección ${ }^{140}$. El jurado sería advertido del interés del testigo, y de cualquier inconsistencia o sospecha de su comportamiento. El testimonio del testigo interesado sería meticulosamente comparado el testimonio de los otros testigos ${ }^{141}$. Finalmente, el testigo sería sujeto a un penetrante contraexamen un sistema que se estimaba el más perfecto y efectivo para revelar la falsedad ${ }^{142}$.

Estos argumentos válidos para los testigos terceros interesados, requerían especiales consideraciones para el caso de las partes del juicio, desde que su testimonio era visto a la vez como uno de los más esenciales y aun el más proclive al perjurio. Entonces, aun cuando Bentham había abogado por la inmediata abolición de todas las reglas de incompetencia, otros que fueron más precavidos prefirieron tomar un paso hasta ese punto, y evaluar sus resultados antes de seguir más allá143. Este patrón incremental sirvió no sólo como una táctica gradual de erosionar la resistencia al cambio, donde un asalto frontal hubiera fracasado, sino que, también preparó el camino para un cambio mayor con un arsenal de precedentes ${ }^{144}$. Esta táctica dio sus frutos en 1851, cuando Lord Brougham

${ }^{136}$ Bentham, Jeremy, A Treatise, cit. nota n. 62, p. 249.

${ }^{137}$ BODANSKY, Joel N., The abolition, cit. nota n. 89, p. 95.

${ }^{138}$ BodAnSky, Joel N., The abolition, cit. nota n. 89, p. 95.

${ }^{139}$ Bodansky, Joel N., The abolition, cit. nota n. 89, p. 95.

${ }^{140}$ Landsman, Stephan, From Gilbert, cit. nota n. 107, p. 1178.

${ }^{141}$ Eardley- Wilmot, John E., Lord Brougham Law's Reform, cit. nota n. 115, p. 55.

${ }^{142}$ BoDANSkY, Joel N., The abolition, cit. nota n. 89, p. 96.

${ }^{143}$ BodAnSky, Joel N., The abolition, cit. nota n. 89, p. 97.

${ }^{144}$ University Of Pennsylvania Law Review, Competency of Witnesses, en The American Law Register 10 (1852-1891), 5, New Series Volume 1 (1862), pp. 258 y 259, disponible en http://www.jstor.org/ stable/3302863, visitado por última vez el 26 de marzo de 2012. 
propuso extender la concesión de competencia para las partes civiles en las cortes superiores. Al dirigirse a la House of Lords, subrayó que la exclusión del testimonio de las partes silenciaba la versión de aquellos que más conocían de la materia en disputa, y que por ello, en muchos casos, una parte, aunque inocente, perdía, solamente por su inhabilidad de ofrecer como evidencia su versión de una transacción sobre la cual no tenía otros testigos ${ }^{145}$.

La sección 2 de la Lord Brougham's Act, establecía que, en los procedimientos que se desarrollan ante cualquier Corte de justicia, las partes de la causa pueden considerarse capaces, y pueden ser compelidas a rendir testimonio; agregando que esto ha de tener lugar según la práctica de la respectiva Corte y, por consiguiente, de viva voz, o sea con la técnica del examen directo y contrainterrogatorio, o bien por deposition ${ }^{146}$, y concluyendo que todo esto pueda tener lugar ya sea a favor o en contra del interés de la parte interrogada. De este modo, quedaba puntualmente excluida la posibilidad de que el instituto hubiese de interpretarse como un instrumento exclusivo o predominantemente entendido, al igual que el descubrimiento por interrogatorios, para promover una confesión ${ }^{147}$.

Las excepciones a la regla, contenidas en la sección 3 del Estatuto, se referían solamente a los procesos penales, a diferencia de las excepciones dispuestas por la sección 4 , donde se establecía que el testimonio de la parte debía quedar excluido en las causas por violación de promesa de matrimonio o de adulterio $^{148}$. Al referirse al Parlamento, Lord Brougham controvirtió que la admisión del testimonio de las partes incrementaría el perjurio en la corte; $y$, que, por el contrario, la admisión de tal testimonio lo reduciría ${ }^{149}$.

La racionalidad de su argumento, según Bodansky constaba de cuatro componentes: i) La exclusión de las partes no previene la ocurrencia del perjurio, y por cierto, alentaba el soborno y el perjurio, cosas que eran más probables que ocurrieran y, más difíciles de detectar por las partes mismas; ii) En la medida en que el testimonio de las partes desplazara la confianza en el testimonio de testigos ordinarios, podría contribuir a la reducción del perjurio exitoso, desde que los juzgadores estarían más alertas y escépticos del testimonio de la parte, precisamente porque su interés era más obvio; iii) Una parte, a diferencia del testigo ordinario, debe generalmente testificar sobre la totalidad del asunto en controversia, más que sobre un punto o tema en particular. Ello genera que su testimonio sea más largo, y en consecuencia, se expone a entregar mayor información infundada so-

\footnotetext{
145 BoDANSky, Joel N., The abolition, cit. nota n. 89, p. 98.

146 Powell, Edmund, The principles, cit. nota n. 116, p. 35.

${ }^{147}$ Cappelletti, Mauro, El testimonio, cit. nota n. 68, p. 19.

${ }^{148}$ Cappelletti, Mauro, El testimonio, cit. nota n. 68 p. 20.

${ }^{149}$ Bodansky, Joel N., The abolition, cit. nota n. 89, p. 98.
} 
bre la cual pueden ser detectadas sus inconsistencias en el contra examen, o por comparación de sus partes con otra evidencia; y iv) Finalmente, la exclusión de las partes como testigos hacía necesario examinar a un número de otras personas y la oportunidad del perjuicio aumenta con el número de testigos ${ }^{150}$.

De acuerdo a lo anterior, el ataque sobre la inadmisibilidad del testimonio de las partes fue basado primeramente en la poca consistencia de esta regla de exclusión del common law, y en la necesidad de reforma en el interés de descubrir la verdad y asegurar justicia.

Sin embargo, los reformadores tuvieron otros argumentos, los cuales se fundaron en la misma matriz: consistencia y economía judicial ${ }^{151}$. Enfatizaron las inconsistencias, identificando numerosas excepciones que habían sido injertadas en la regla de exclusión y que habían dado lugar a distinciones artificiales e ilógicas, que tiñeron el proceso judicial y hecho una parodia de la supuesta racionalidad de la exclusión. Notaron también el tratamiento inconsistente de los casos civiles y criminales, en tanto se permitía al fiscal y no al acusado testificar bajo juramento en los casos criminales ${ }^{152}$.

Los reformadores enfatizaron que mientras el testimonio de las partes fue excluido de las cortes superiores de common law, donde este podía ser testeado en el contrainterrogatorio y estaba sujeto a escrutinio por el Juez y el Jurado, fue en los hechos permitido en otros escenarios procesales donde aquellas salvaguardias faltaban, es decir, precisamente en aquellas situaciones donde se estaba más expuesto al riesgo del falso juramento ${ }^{153}$. Lord Brougham sintetizó el problema sosteniendo que en las interrogaciones en Equity, el riesgo de perjurio era incalculablemente mayor, porque la examinación de cada parte era conducida a espaldas de los otros, bajo el consejo de un hombre profesional, sin el riesgo de exposición al adversario, y sin el control del juez ${ }^{154}$.

Finalmente observaron que en las Cortes del Condado, el Common Law tuvo dos sistemas diferentes de procedimiento, basados en la admisión del testimonio de las partes si la cantidad en controversia era mayor o menor a 50 libras, una distinción que los reformistas atacaron como absurda. En efecto, la English County Court Acts de 1846 permitió a las partes testificar como testigos en los casos pendientes ante esta Corte inferior ${ }^{155}$.

\footnotetext{
${ }^{150}$ BODANSky, Joel N., The abolition, cit. nota n. 89, pp. 98-99.

151 BoDANSKY, Joel N., The abolition, cit. nota n. 89, p. 99.

152 Bodansky, Joel N., The abolition, cit. nota n. 89, p. 99.

${ }^{153}$ Eardiey-Wilmot, John E., Lord Brougham Law's Reform, cit. nota n. 115, p. 55.

${ }^{154}$ BODANSKY, Joel N., The abolition, cit. nota n. 89, p. 101.

${ }^{155}$ Verkerk, Remme, Fact-Finding in Civil Litigation. A Comparative Perspective, $1^{\text {a }}$ edición, Intersentia, Portland, 2010, p. 219.
} 
Un argumento de economía procesal, fue desarrollado subrayando la demora y gastos que creaba la regla de exclusión del common law, tanto porque negaba la más eficiente fuente de información a los juzgadores, tanto porque demandaba la producción de más testigos ${ }^{156}$.

Además de estos argumentos se añadió una apelación a los propios intereses de la comunidad legal. A la exclusión del testimonio de la parte en Inglaterra se le hizo responsable de un marcado cambio en la litigación desde las Cortes superiores hacia las Cortes del Condado ${ }^{157}$. De este modo, se dijo que la salvación de las Cortes Superiores dependía de la rápida aprobación del Acta de Lord Brougham. Los reformadores sostuvieron que la continua pérdida de trabajo para las Cortes del Condado, Ilevarían a la "miseria de la barra" y la ruina de muchos ${ }^{158}$.

La oposición a la propuesta de reforma de Lord Brougham fue el resultado de dos factores, el temor del perjurio y la inercia de la profesión legal. Aun cuando la reforma finalmente fue aprobada por el Parlamento por amplio margen, enfrentó una considerable oposición de la barra organizada, los jueces del common law y, en la House of Lords, del Lord Chancellor ${ }^{159}$. La respuesta de los reformadores sobre el temor al perjurio ha sido apuntada anteriormente. Además, desestimaron el argumento de que el Acta proponía una innovación no probada, citando la experiencia de las County Court, y señalando que el testimonio de las partes era, en la práctica permitida, de una manera u otra, en todas las Cortes menos en las Cortes superiores de common law ${ }^{160}$.

En el debate desarrollado en la House of Lords sobre el Acta de Lord Brougham, el Chancellor sugirió que el sistema existente, donde las partes sólo hablaban a través de sus abogados, al menos alcanzaban una tosca igualdad entre las partes opuestas, mientras que la concesión de competencia causaría que los resultados de los juicios se volverían mayormente en la destreza accidental y persuasividad de las partes, dándoles una ventaja a aquellos de mayor inteligencia y de conducta agradable. Lord Brougham rechazó este argumento, anotando que precisamente la misma objeción podría ser aplicable a cualquier testigo $^{161}$.

La evolución de la regla en Inglaterra influyó decididamente en los Estados Unidos que en menos de cincuenta años, eliminaron las exclusiones fundadas

\footnotetext{
${ }^{156}$ BODANSKY, Joel N., The abolition, cit. nota n. 89, p. 102.

157 BODANSKY, Joel N., The abolition, cit. nota n. 89, p. 103.

${ }^{158}$ BODANSky, Joel N., The abolition, cit. nota n. 89, p. 103.

${ }^{159}$ Eardiey-Wilmot, John E., Lord Brougham Law's Reform, cit. nota n. 115, p. 215.

${ }^{160}$ Cappelletti, Mauro, El testimonio, cit. nota n. 68, p. 29.

161 BoDAnSKY, Joel N., The abolition, cit. nota n. 89, p. 105.
} 
en intereses. ${ }^{162}$ Entrado el siglo XX sólo Georgia mantenía la regla de exclusión, y para entonces sólo para casos con acusados criminalmente, una anomalía que finalizó en 1962, con el fallo de la Corte Suprema Federal en el caso Ferguson versus Georgia, que generó la reforma en la legislatura de Georgia ${ }^{163}$. Sin embargo, la experiencia Americana difiere de la inglesa en un aspecto significativo, la residual oposición a la competencia se manifestó en la forma del "Dead Man's Statutes"164, el cual fue establecido en todo el país casi al mismo tiempo, y frecuentemente como parte del mismo Estatuto de concesión general de competencia ${ }^{165}$.

\section{La declaración de parte en Austria}

En el sistema del civil law el dominio del viejo y escrito procedimiento del ius commune, un procedimiento muy similar a la practica en equidad, se quebró solo después de una larga y amarga lucha que duró 300 años y que culminó con la adopción de los Códigos de los siglos XVIII y XIX ${ }^{166}$.

En efecto, en Austria la Ordenanza Judicial General, de 1 de mayo de 1781 consagró un procedimiento escrito, y en los cuales la interrogación de los testigos, en general, fue recibida bajo el formato de artículos de prueba ${ }^{167}$. Esta situación cambió en 1873 para las pequeñas causas con la implementación del Bagatellverfahren (procedimiento de menor cuantía), la que se caracterizó por la oralidad, inmediación y libre valoración de las pruebas ${ }^{168}$.

\footnotetext{
162 Morgan, Edmund L., "The Future of the Law of Evidence", Texas Law Review, Vol. 29, 1951, p. 588.

${ }^{163}$ Cfr. Ferguson v. Georgia, 81 S.Ct. 756.

${ }^{164}$ Sobre el contenido e historia de la regla del Dead Man's Statute, Cfr. Broun, Kenneth S., McCormick On Evidence, cit. nota n. 69, pp. 119 a 121; PAGE, Wesley P., "Dead man talking: A historical analysis of West Virginia's dead man's statute and a recommendation for reform", West Virginia Law Review, 2007, pp. 897-927; Dibley, Kristen, "The deadman's statutes-who is an interested party in wisconsin?", Marquette Law Review, Vol. 87, 2004, pp. 1025-1039.

${ }^{165}$ Esta regla excluye el testimonio de un sobreviviente que había celebrado una transacción con una persona ahora fallecida, cuando el testimonio era ofrecido contra su sucesión. Codificaciones modernas, como las Federal Rules of Evidence, no preservan el "Dead Man's Statute", sin embargo, esta regla sobrevive en numerosas legislaciones estaduales. La prevalencia de esta excepción ilustra lo extendido que el miedo al perjurio continuó preocupando a los legisladores. PAGE, Wesley P., Dead man, cit. nota n. 164, p. 900.

166 Homburger, Adolf, "Functions of Orality in Austrian and American Civil Procedure", Buffalo Law Review, Vol. 20, 1970-1971, p. 11.

167 Engelmann, Arthur, History of Continental Civil Procedure, Traducción al inglés de Robert Wynes Millar, Little, Brown and Company, Boston, 1927, pp. 629 y 630.

${ }^{168}$ VAn Rhee, C.H., "The Development of Civil Procedural Law in Twentieth-Century Europe: From party Autonomy to Judicial Case Management and Efficiency", en C.H. Van Rhee (editor), Judicial Case Management and Efficiency in Civil Litigation, Intersentia, Antwerpen, 2008, p. 11.
} 
La oralidad fue uno de los temas centrales del movimiento de reforma continental, ya que representó una nueva doctrina procesal incluyendo no sólo una audiencia oral central, sino también los principios relacionados de inmediación, publicidad, concentración libre evaluación de la prueba y aumento de la autoridad judicial, los cuales encontraron expresión en diferentes grados en las legislaciones ${ }^{169}$.

\section{a) El quiebre con el sistema romano canónico. Nuevos principios inspiradores del proceso civil}

En Austria, el interrogatorio libre de parte, fue implementado en los años 1873 y 1895, como medio de prueba inspirado por el modelo inglés ${ }^{170}$. Para que pudiera triunfar el instituto de la declaración de parte con fines probatorios, consigna Cappelletti, debía desaparecer un principio que había permanecido en la base del derecho procesal austriaco, según el cual, la pro se declaratio de la parte constituía una mera afirmación, una mera alegación por su naturaleza intrínseca, no susceptible de valoración probatoria por el Juez ${ }^{171}$. El precedente inglés fue esgrimido por Glaser en 1865 para reemplazar el juramento por la declaración libre de la parte ${ }^{172}$. Glaser se convirtió en Ministro de Justicia de Austria en 1871 e implementó sus ideas en la Ley sobre Procedimiento de Pequeñas Causas (Bagatellverfahren) de 1873. El juramento formal de las partes no sería aplicable y, el juez podría ordenar, que se escuchara a las partes como un testigo, a petición de ellas mismas, o de oficio, si la evidencia presentada por las partes era insuficiente ${ }^{173}$.

El Bagatellverfahren, entonces, fue la primera pieza moderna de la legislación procedimental austriaca siguiendo los principios de oralidad, inmediación y libre valoración de la prueba ${ }^{174}$. Con dicha ley ese proceso, relativo a causas de valor económico exiguo, fue asentado el principio de la oralidad y, por ende, el rechazo del sistema formal de valoración de las declaraciones informativas de los terceros y de las partes ${ }^{175}$. Se introducía, al fin, el instituto del interrogatorio

\footnotetext{
${ }^{169}$ Homburger, Adolf, Functions of Orality, cit. nota n. 166, p. 11.

${ }^{170}$ Cappelletti, Mauro, El testimonio, cit. nota n. 68, p. 70.

171 Cappelletti, Mauro, El testimonio, cit. nota n. 68, p. 73.

172 Cappelletti, Mauro, El testimonio, cit. nota n. 68, p. 74.

${ }^{173}$ Engelmann, Arthur, History of Continental Civil Procedure, cit. nota n. 167, p. 633.

${ }^{174}$ Oberhammer, P., "Speeding up civil litigation in Austria: past and present instruments", en The Law's Delay: Essay on Undue delay civil in litigation, VAN RHEE, C.H. (editor), Intersentia, Antwerpen, 2004, p. 222 .

${ }^{175}$ LeNHOfF, Arthur, "The Law of Evidence A Comparative Study Based Essentially on Austrian and New York Law", American Journal of Comparative Law, Vol. 3, 1954, p. 316.
} 
libre y jurado de las partes en calidad de testigos, basándose en el modelo inglés, con la única diferencia que en la ley de 1873, fue considerado un medio de prueba subsidiario ${ }^{176}$.

Franz Klein consideró el juramento formal como una ordalía o un duelo, como un vestigio del procedimiento temprano medieval. De acuerdo con ello, el Código Austriaco de Procedimiento Civil de 1895 reemplazó el juramento formal de las partes por un nuevo sistema ${ }^{177}$. En efecto, el Código de Procedimiento Civil de 1895, obra de Franz Klein, fue la primera legislación que pavimentó el camino a la abolición del juramento formal de las partes, rechazándolo, por considerarlo un producto de una ideología religiosa más que de la razón. Aún más, Klein estimó que estos juramentos no calzaban dentro de un sistema legal que proclamaba una libre evaluación de la evidencia ${ }^{178}$. En efecto, se ha destacado que lo más notable de la Ordenanza Austriaca fue la abolición del interrogatorio, la comparecencia de las partes, la positio y el juramento probatorio, reemplazándolos por un medio sin duda alguna mejor: el examen de las partes, simple o jurado ${ }^{179}$.

Klein, como se ha visto, tuvo una actitud positiva hacia el derecho inglés con respecto al interrogatorio de las partes y al interrogatorio de las partes según la Ley de Procedimiento de Pequeñas Causas de $1873^{180}$. Van Rhee explica que Klein comentó el Procedimiento Civil inglés en su libro Pro Futuro y mencionó algunas materias tales como el desacato de la corte, el discovery a través de interrogatorios y la etapa preparatoria del procedimiento ${ }^{181}$. La percepción de Klein de la litigación civil como una búsqueda de la verdad sustantiva, implicó que cada parte podía pedir la interrogación de su oponente sobre hechos y circunstancias desconocidas para ella o también sobre sus pruebas. Estas ideas, según Van Rhee, nos asocian con el anglo Americano "discovery" (actualmente conocido como "disclosure" en Inglaterra) y esto sería apropiado: Klein mismo asoció esto con aquel procedimiento ${ }^{182}$.

Quizás la tarea más compleja de Klein fue enfrentar la delimitación de funciones entre el Tribunal y las partes en un sistema que intentaba combinar ca-

\footnotetext{
${ }^{176}$ Cappelletti, Mauro, El testimonio, cit. nota n. 68, p. 76.

177 LeNHOFF, Arthur, The Law of Evidence, cit. nota n. 175, p. 340.

${ }^{178}$ Verkerk, Remme, Fact-Finding in civil Litigation, cit. nota n. 155, p. 75.

${ }^{179}$ Lessona, Carlos, Teoría General de la Prueba en Derecho Civil, Tomo I, traducción de Aguilera de Paz, Enrique, 2a edición, Revista de Legislación Madrid, 1906, p. 585.

180 Verkerk, Remme, Fact-Finding in civil Litigation, cit. nota n. 155, p. 75.

181 Van Rhee, C.H., "Evolución del Derecho Procesal en Europa: Cómo el juez activo se convirtió en lo normal", Revista Chilena de Derecho y Ciencia Política, Vol. 2, 2011, p. 30.

182 Van Rhee, C.H., The Development of Civil Procedural Law, cit. nota n. 168, p. 14.
} 
racterísticas de los principios dispositivo y de investigación oficial ${ }^{183}$. El principio dispositivo es compañero de un sistema construido sobre derechos sustantivos que reconoce derechos privados y deberes. Esto garantiza al demandante el derecho a decidir si demanda o no, a quien demandar y cuando hacerlo; y para el demandado el correspondiente derecho de admitir la demanda o resistirla. La destrucción del principio dispositivo causaría la caída del sistema entero de derechos y deberes privados. El principio de oficialidad, de otro lado, reconoce un interés público predominante en la justa, rápida y económica determinación de las acciones civiles ${ }^{184}$.

Para Klein, una controversia legal era considerada una enfermedad social para la cual el derecho sustantivo proveía el remedio. El proceso, entonces, cumple el rol de un medico que diagnóstica una enfermedad y prescribe la cura como un servicio social para el bienestar de la sociedad y también del litigante individual. Los dos principios no son irreconciliables, pero su coexistencia crea tensiones y fricciones que requieren un cuidadoso balance ${ }^{185}$.

En este contexto el Código Procesal Civil de 1895 derogó el juramento formal de la parte. La redacción final de las reglas fue una cuidadosa fórmula de compromiso entre el juramento de la parte por un lado y la libre interrogación de las partes como testigos por el otro. A diferencia del derecho inglés y de la Ley sobre Procedimientos en Pequeñas Causas, el Código de 1895 no permitió a las partes ser escuchadas como testigos. De hecho, la declaración de parte (Parteivernehmung) fue introducida como un medio de prueba separado, y no considerada como testimonial ${ }^{186}$. El examen debe hacerse ante el Tribunal que conoce del asunto, y sólo se consiente la delegación cuando la parte no puede comparecer por causa de impedimento insuperable o cuando las costas de la comparecencia fueran desproporcionadas ${ }^{187}$.

Las características distintivas más importantes del instituto, eran: primero, la interrogación de las partes se dividió en dos etapas, una primera obligatoria en que las partes serían libremente interrogadas sin estar bajo juramento, y si el juez creía que ésta libre interrogación no era suficiente para determinar la verdad de una proposición de hecho el juez podía proceder a una segunda etapa opcional, y, ordenando la interrogación de las partes bajo juramento ${ }^{188}$; segundo, la interrogación de las partes fue un medio de prueba subsidiario.

\footnotetext{
${ }^{183}$ Homburger, Adolf, Functions of Orality, cit. nota n. 166, p. 24.

184 Homburger, Adolf, Functions of Orality, cit. nota n. 166, p. 24.

${ }^{185}$ Homburger, Adolf, Functions of Orality, cit. nota n. 166, p. 24.

${ }^{186}$ LeNHOFF, Arthur, The Law of Evidence, cit. nota n. 175, p. 341.

${ }^{187}$ Lessona, Carlos, Teoría general de la Prueba, cit. nota n. 179, p. 586.

${ }^{188}$ VERKEK, Remme, Fact Finding, cit. nota n. 155, p. 221.
} 
La interrogación, por sí misma, no podía proveer de plena prueba sobre un asunto de hecho. Esta regla es un resabio de la práctica medieval, en la cual el juramento suplementario sería considerado como media prueba ${ }^{189}$. Más aún, la interrogación de parte fue considerada un medio de prueba que sólo sería necesario si la otra evidencia presentada no era conclusiva sobre la materia de hecho después que toda la evidencia había sido presentada ${ }^{190}$. La tercera característica destacable de la interrogación de las partes, es que sólo una de esas partes podía ser interrogada bajo juramento ${ }^{191}$. La última característica distintiva de la interrogación de partes es que ellas podían no ser físicamente compelidas a testificar en la Corte. La deposición de la parte, como también la negativa a prestarlo o la incomparecencia, estaban sujetas a la libre valoración judicial. Comparecencia y deposición no podían ser impuestas coactivamente. El deber de decir la verdad era sancionado, también para la deposición no jurada, con las mismas penas conminadas para el testimonio falso (de los terceros) ${ }^{192}$. Esta regla aún existe. Si una parte, sin una válida justificación, rehúsa comparecer en la Corte o dar respuesta a las preguntas, el juez podrá tomar esto en consideración cuando evalúe libremente toda la evidencia ${ }^{193}$. La distinción entre los institutos del Fragerecht, esto es, el interrogatorio con fines clarificadores de la situación de hecho alegado, y de la Parteivernehmung, o sea, del interrogatorio con finalidad probatoria, estaba concebida por la ley con gran claridad ${ }^{194}$. Se ha destacado la amplitud del poder discrecional que se concedió al Juez en la prueba por examen de la partes, lo que refleja la confianza del legislador austriaco en el Magistrado ${ }^{195}$.

\section{b) La influencia del modelo Austriaco}

La influencia de Austria en la expansión de la declaración libre de la parte fue muy importante. Los cambios ingleses habían sido vistos con interés en las jurisdicciones continentales, aun cuando fueron frecuentemente considerados muy radicales. Los legisladores habían estado vacilantes en permitir a las partes tomar el estrado como testigo y testificar bajo juramento. Incluso en Europa, hoy día se pueden encontrar muchas regulaciones sobre la interrogación de partes

\footnotetext{
${ }^{189}$ VERKEK, Remme, Fact Finding, cit. nota n. 155, p. 221.

190 VERKEK, Remme, Fact Finding, cit. nota n. 155, p. 221.

191 VERKEK, Remme, Fact Finding, cit. nota n. 155. Ibídem, p. 221.

192 Cappelletti, Mauro, El testimonio, cit. nota n. 68, p. 77.

${ }^{193}$ VERKEK, Remme, Fact Finding, cit. nota n. 155, p. 221.

${ }^{194}$ Cappelletti, Mauro, El testimonio, cit. nota n. 68, p. 75.

${ }^{195}$ LessonA, Carlos, Teoría general de la Prueba. cit. nota n. 179, p. 586.
} 
que no permiten que ellas testifiquen bajo juramento ${ }^{196}$. Las normas austriacas de 1895 sobre la interrogación de las partes fueron consideradas una alternativa razonable y trasplantadas a otros países de Europa.

Las innovaciones austriacas de 1873 y 1875, influyeron en el Código de Procedimiento Civil de Japón (1898), Hungría (1911), y Polonia (1930). La declaración de partes también fue adoptada por Noruega (1915), Dinamarca (1916). También Suecia (1942), muestra influencia en este punto del Código Austriaco $^{197}$. En un número de Cantones suizos, se mantiene una distinción entre el testimonio de los testigos y de las partes. Aun cuando las partes no son técnicamente testigos, la Corte puede pedir a las partes que responda preguntas específicas, lo que es frecuente cuando el conocimiento de una de las partes es particularmente importante para el resultado del juicio y la Corte no tiene otro medio para establecer la verdad del hecho ${ }^{198}$. Reglas inspiradas en el Código Austriaco fueron incorporadas, pero con modificaciones, en Alemania y Croacia ${ }^{199}$.

Para Cappelletti el carácter social del Código Austríaco fue concebido por Klein de manera quizá demasiado vaga como para que pudiese ser traducido cómodamente en fórmulas jurídicas claras; y el problema de la distinción entre el principio dispositivo, por un lado, y los principios de la sustanciación y de la dirección de oficio, por el otro, aún no había hallado en aquel tiempo en la doctrina una solución totalmente satisfactoria ${ }^{200}$. Más de una norma, y más de un instituto, pero sobre todo el instituto del interrogatorio de las partes, cobraron así en el Código de 1895 un significado ambiguo, con una función que pareciera estar a mitad de camino entre la de una simple asistencia prestada por el juez a las partes para que no caigan víctimas de las formalidades procesales o de una defensa ineficiente, y la función de una verdadera y propia inquisición ${ }^{201}$.

En 1983 el Acta de reforma austriaca hizo dos significativas reformas a las reglas sobre la interrogación de las partes. Primero, abolió el carácter subsidiario de la interrogación de las partes, considerando que ello no calzaba en un sistema en la cual la evidencia es libremente evaluada por el juez ${ }^{202}$. Segundo, la

\footnotetext{
196 VERKEK, Remme, Fact Finding, cit. nota n. 155, p. 223.

${ }^{197}$ LeNHOFF, Arthur, The Law of Evidence, cit. nota n. 175, p. 342.

198 Baumgartner, Samuel P., "Civil Procedure Reform in Switzerland and the Role of Legal Transplants", Supreme Court Law Review, Vol. 49, 2010, p. 83.

199 VERKEK, Remme, Fact Finding, cit. nota n. 155, pp. 224 y 225.

${ }^{200}$ Cappelletti, Mauro, El testimonio, cit. nota n. 68, p. 78.

${ }^{201}$ Cappelletti, Mauro, El testimonio, cit. nota n. 68, p. 78.

202 VERKEK, Remme, Fact Finding, cit. nota n. 155, p. 222.
} 
reforma de 1983 hizo posible la interrogación de ambas partes bajo juramento, removiendo aquella característica que se mostraba más claramente influenciada por el juramento suplementario, demostrando con ello un verdadero quiebre con la herencia romano-canónico en esta área ${ }^{203}$.

\section{CONCLUSIONES}

La investigación que se ha desarrollado nos permite concluir que, detrás de la evolución histórica en el tratamiento de la utilización del saber de las partes con fines probatorios, se encuentra un factor común: la búsqueda de un escenario que permita al ente adjudicador realizar la mejor determinación de los hechos, en la búsqueda de una solución justa de los conflictos.

Este proceso se inserta, en términos macroscópicos, en una crítica al formalismo y falta de racionalidad del sistema de prueba, que atenta contra el objetivo que se ha apuntado. Esta crítica fue liderada por destacados juristas que promovían la libertad de prueba como Bentham y sus discípulos.

La corriente reformista desarrollada en Inglaterra influyó también en Austria, donde Franz Klein, eliminó el juramento e incorporó la declaración libre de las partes. La regulación normativa específica de este instituto y el carácter social del proceso de la Ordenanza Procesal Austriaca, como apuntaba Cappelletti, pudo, sin embargo, resultar algo ambigua, especialmente sobre la función específica que cumplía el interrogatorio libre frente al juez, esto es, no tanto como elemento probatorio sino que como un espacio de intervención de los poderes que se le entregaban al juez.

Los cambios en los códigos continentales dan cuenta de cierta persistencia de la herencia de las antiguas reglas de prueba legal, tales como el juramento y los interrogatorios. Esto podría explicar la creación de grupos de reglas diferenciadas, unas aplicables a la examinación de testigos y otras reglas ligeramente diferentes aplicables a las partes.

La investigación que se ha desarrollado a propósito de este trabajo, cobrará vigencia para nuestro país. En efecto, a pesar de las conocidas dificultades de comparar sistemas distintos, sobretodo en épocas diferentes, podemos constatar ciertos patrones similares que pueden ser orientadores de nuestro propio proceso de cambio.

Por una parte, hay un proceso consistente de trasformación del sistema de justicia, que avanza hacia la consolidación del principio de la oralidad, especialmente en la recepción de las pruebas, similar al observado en los dos sistemas analizados.

${ }^{203}$ Verkek, Remme, Fact Finding, cit. nota n. 155 p. 222. 
A esta dinámica se une el hecho que la libertad de prueba, y valoración libre, ya se encuentran asentados normativamente en los procesos reformados en materia procesal penal, de familia y laboral, lo que evidencia una inconsistencia con el sistema procesal civil actual, es decir, escenarios que admiten normativamente la interrogación libre de las partes. De esta forma, surge un argumento similar al que registrábamos en Inglaterra y Austria, los que al tiempo de la abolición legislativa de las reglas de exclusión, también presentaban espacios que permitían la posibilidad de una declaración libre de las partes, como era la situación de las Cortes de Equity en Inglaterra y los procedimientos de pequeñas causas en Austria. Esta realidad, como se observó, debilitó los argumentos que resistían la incorporación del testimonio libre de las partes, desde que las razones para sostener la exclusión no eran consistentes al examinar el sistema en su conjunto.

De otro lado, en nuestro país también es posible observar una crítica doctrinaria al formalismo en los procedimientos y a las restricciones probatorias del sistema civil, paradigmáticamente reflejado en la existencia de un Proyecto de nuevo Código Procesal Civil, apoyado por importantes sectores de la academia. Aun cuando no hemos podido registrar una preocupación consistente sobre el tema específico de la declaración de parte, sin duda que se ha configurado un escenario favorable a éste, por la búsqueda de espacios que permitan contar con mayor información para el establecimiento de los hechos y alcanzar la justicia en la decisión judicial. Desde distintas realidades institucionales, este contexto también se experimentó en Inglaterra y Austria, en los cuales una corriente doctrinaria vigorosa e influyente empujó en el mismo sentido.

También puede advertirse que una transformación tan intensa generará resistencias culturales, basadas en los prejuicios que subyacen en la estructura normativa que desaparecerá. Si bien en el caso inglés, el debate evidenció una fuerte preocupación por el aumento del riesgo de perjurio, también fue posible constatar la existencia de otras preocupaciones igualmente poderosas, como la economía procesal, la consistencia del sistema legal, la solidez de las reglas de exclusión de la evidencia; la función apropiada del proceso adversarial, y la creciente presencia de abogados en la operatoria del sistema de justicia. Cuestionamientos similares pueden salir al paso de la reforma a nuestro proceso civil a propósito del instituto que hemos estudiado.

En definitiva, si nuestro objetivo es consolidar un sistema de mayor justicia, y ello depende de la capacidad de entregar al juzgador la mejor y más completa información disponible, no se ven argumentos de peso que justifiquen excluir la valiosa información que poseen las partes. La dificultad en asentar los nuevos paradigmas y enfrentar los problemas operativos que, sin duda, se presentarán, serán el contexto sobre el cual se debatirá este asunto. 


\section{BibLiOGRAFíA}

Abraham, Kenneth, "The Common Law Prohibition on Party Testimony and the Development of Tort Liability", en Virginia Law Review 95 (2009) 3.

Aguilar Aranela, Cristián, La Prueba en el Proceso Penal Oral (1 $1^{a}$ edición, Santiago, Sociedad Editora Metropolitana Ltda., 2003).

Alcaíno Torres, Rodrigo y Cortés De La Cerda, Matías, Curso Elemental de Litigación Oral ( $1^{\text {a }}$ edición, Santiago, Editorial Jurídica de Chile Colección Manuales Jurídicos, 2012).

Baeza, Gloria, y Pérez, Jaime, Los Nuevos Tribunales de Familia, Procedimiento Ordinario (2a edición, Santiago, LegalPublishing, 2008).

Baumgartner, Samuel P., "Civil Procedure Reform in Switzerland and the Role of Legal Transplants", en Supreme Court Law Review 49 (2010).

Bello, Andrés, Obras Completas. Tomo Quinto. Proyecto de Código Civil (Santiago, 1932) III.

, Belto, Andrés, Obras Completas de don Andrés Bello, Opúsculos Jurídicos Volumen IX (edición hecha bajo la dirección del Consejo de Instrucción Pública en cumplimiento de la lei de 5 de septiembre de 1872, Santiago, Impreso por Pedro G. Ramírez, 1881-1883).

Benavente Gorroño, Darío, Derecho Procesal Civil. Juicio Ordinario y Recursos Procesales (5a edición, Santiago, Editorial Jurídica de Chile, 2004).

Bentham, Jeremy, A treatise on judicial evidence ( $1^{\text {a }}$ edición, London, Messrs. Baldwin, Cradock and Joy, Paternoster-Row, 1825), I, II y III.

, Rationale of Judicial Evidence, (London, Hunt and Clarke, 1827) 4.

BODANSKY, Joel N., "The abolition of the party-witness disqualification: an historical survey", en Kentucky Law Journal 70 (1981).

Broun, Kenneth S., McCormick On Evidence (6 ${ }^{a}$ edición, United States of América, Thomson West, 2006).

Candia Guzmán, Claudio y Koch Cid, Karla, Reforma Procesal del Trabajo, (2a edición, Santiago, Editorial Metropolitana, 2009).

Capallı, Richard, "Procedimiento Civil Comparado: Estados Unidos, Chile y Sudamérica", en Revista Chilena de Derecho 19 (1992).

CappellettI, Mauro, La oralidad y las pruebas en el proceso civil (1 $1^{\text {a }}$ edición, Buenos Aires, Ediciones Jurídicas Europa-América S., 1972).

, El proceso civil en el Derecho comparado. Las grandes tendencias evolutivas ( $1^{a}$ edición, traducción de Santiago Sentis Melendo, Buenos Aires, Ediciones Jurídicas Europa-América S.A., 1973).

- El testimonio de la parte en el sistema de la oralidad. Contribución de la teoría de la utilización probatoria del saber de las partes en el proceso civil 
( $1^{\text {a }}$ edición, traducción castellana de Tomás A. Banzhaf, La Plata, Editora Platense, 2002), I y II.

CarneluttI, Franceso, La prueba civil ( $3^{\text {a }}$ edición, traducción castellana de Niceto Alcalá-Zamora y Castillo, Buenos Aires, Arayú, 1955).

Caroca, Alex, "Recuperación de la Importancia de la Prueba en un Modelo Procesal Civil Oral", en De la Oliva, Andrés y Palomo Vélez, Diego (Coordinadores), Proceso Civil, Hacia una Nueva Justicia Civil (Editorial Jurídica de Chile, 2007).

Carpi, Federico; Ortells Ramos, Manuel (editores) Oralidad y escritura en un proceso civil eficiente. Oral and Written Proceedings: Efficiency in Civil Procedure ( $1^{\text {a }}$ edición, Valencia, Universitat de Valéncia, 2008), I y II.

Claro Solar, Luis, Explicaciones de derecho civil y comparado (Santiago, 1939).

Clermont, Kevin M., Principles of civil procedure (Minessota, $2^{\text {a }}$ edición, Thompson West, 2009).

Colquitt, Joseph A.; Gamble, Charles W., "From incompetency to weight and credibility: the next step in an historic trend", en Alabama Law Review 47:1 (1995).

Correa Selamé, Jorge, Derecho Procesal de Familia (1 ${ }^{\text {a }}$ edición, Santiago, Thomson Reuters Punto Lex, 2009).

Damaska, Mirjan R., The Faces of Justice and the State Authority. A Comparative Approach of the Legal Process ( $1^{\text {a }}$ edición, Yale, Yale University Press, 1986).

De SANTO, Víctor, La prueba judicial. Teoría y práctica ( $1^{\text {a }}$ edición, Buenos Aires, Universidad, 1992).

Devis Echandía, Hernando, Compendio de la Prueba Judicial (versión 2000, anotado y concordado por Adolfo Alvarado Velloso, Buenos Aires, RubinzalCulzoni, 2000), I y II.

DiвLEY, Kristen, "The deadman's statutes-who is an interested party in wisconsin?", en Marquette Law Review 87 (2004).

Duce, Mauricio; Marín, Felipe; Riego, Cristián, "Reformas a los procesos Civiles Orales: Consideraciones desde el debido proceso y la calidad de la información", en CABEZÓN, Andrea (Coordinadora) Justicia Civil: Perspectiva para una reforma en América Latina, (Centro de Estudios de Justicia de las Américas, Santiago, 2008).

Eardley-Wilmot, John E., Lord Brougham Law's Reform (London, Longman, Brown, Green, Longman and Roberts, 1860).

Engelmann, Arthur, History of Continental Civil Procedure (traducción al inglés de Robert Wynes Millar, Boston, Little, Brown and Company, 1927). 
Fernández Toledo, Raúl, Las Facultades y Deberes del Juez en materia Probatoria en el Proceso Laboral. Análisis Crítico ( $1^{\text {a }}$ edición, Santiago, Thomson Reuter Punto Lex, 2011).

Fuentes, Claudio, "La persistencia de la prueba legal en la judicatura de Familia", en Revista de Derecho de la Universidad Católica del Norte 18 (2011) 1.

García Goyena, Florencio, Concordancias, Motivos y Comentarios del Código Civil Español (Zaragoza 1974).

GOODHART, Arthur L., "A Changing Approach to the Law of Evidence", en Virginia Law Review 51 (1965), 5.

Gorphe, François, La crítica del testimonio ( $6^{a}$ edición, traducción española de la segunda edición francesa de Mariano Ruíz-Funes, Madrid, Reus, 2003).

Guzmán Brito, Alejandro, La Codificación Civil en Iberoamérica, Siglos XIX y $X X,($ Santiago, 2000).

Hamowr, Roland, "F. A. Hayek and the common law", en Cato Journal 23 (2003) 2. HOMbURGer, Adolf, "Functions of Orality in Austrian and American Civil Procedure", en Buffalo Law Review, 20 (1970-1971).

Jolowicz, J. A., On civil procedure ( $1^{\text {a }}$ edición, Great Britain, Cambridge University Press, 2000).

KeAne, Adrian, The modern Law of Evidence (Gran Bretaña, $7^{\mathrm{a}}$ edición, Oxford University Press, 2008).

Kielmanovich, Jorge L., Medios de Prueba ( $1^{\text {a }}$ edición, Buenos Aires, AbeledoPerrot, 1993).

Landsman, Stephan, "The Rise Of The Contentious Spirit: Adversary Procedure In Eighteenth Century England", en Cornell Law Review (1989-1990), 75.

_ _ "From Gilbert to Bentham: The reconceptualization of evidence theory", en The Wayne Law Review 36 (1990).

LANGBEIN, John H., "The Historical foundations of the law of evidence: a view from the ryder sources", en Columbia Law Review 96 (1996).

,"The Prosecutorial Origins of Defence Counsel in The Eighteenth Century: The Appearance of Solicitors", en Cambridge Law Journal, 58(2), July 1999.

"The Criminal Trial before the Lawyers", en The University of Chicago Law Review 45 (1978).

, "Shaping the Eighteenth-Century Criminal Trial: A View from the Ryder Sources", en The University of Chicago Law Review 50 (1983) 1.

, "The Privilege and Common Law Criminal Procedure: The Sixteenth to the Eighteenth Centuries", en Helmholz, R. H. (ed.) The Privilege against Self-Incrimination. Its Origins and Developments (Chicago, University of Chicago Press, 1997). 
, "Judges and Judging in the history of common law and civil law: From antiquity to modern time", Cambridge University Press (2012).

, "The Disappearance of Civil Trial in the United States", en Yale Law Journal (2012).

LANGer, Máximo, "Revolution in Latin América Criminal Procedure: Diffusion of legal ideas from the periphery", en American Journal of Comparative Law 55 (2007).

Larroucau Torres, Jorge, Por un estándar amplio de admisibilidad de pruebas en la justicia civil, en Libro Homenaje al Centenario de la Facultad de Derecho de la Universidad de Valparaíso (Valparaíso, Edeval, 2012).

LeNHOFF, Arthur, "The Law of Evidence A Comparative Study Based Essentially on Austrian and New York Law", en American Journal of Comparative Law, 3 (1954).

Lessona, Carlos, Teoría general de la Prueba en Derecho Civil. (Traducción de Aguilera de Paz, Enrique, $2^{a}$ edición, Madrid, Revista de Legislación, 1906) I.

López Díaz, Carlos, Manual de Derecho de Familia y Tribunales de Familia (1 ${ }^{\text {a }}$ edición, Santiago, Librotecnia, 2005), II.

Marcus, Richard L., "Putting American procedural exceptionalism into a globalized context", en The American Journal of Comparative Law 53 (2005).

Marín Verdugo, Felipe, "Declaración de parte como testigo", en Revista lus et Praxis 16 (2010).

Morgan, Edmund M., "The future of the law of evidence", en Texas Law Review 29 (1951).

_ "The Jury And The Exclusionary Rules Of Evidence", en The University of Chicago Law Review. 4 (1937), 2.

Montero Aroca, Juan, La herencia procesal (México, 1994).

Nisboer, J.F., "Common Law Tradition In Evidence Scholarship Observed From A Continental Perspective", en The American Journal of Comparative Law 41 (1993).

NokEs, G.D., "The English Jury and the Law of Evidence", en Tulane Law Review 31 (1956-1957).

NúÑez, Raúl, "Crónica sobre la Reforma del Sistema Procesal Civil Chileno (Fundamento, Historia y principios)", en De La Oliva, Andrés y Palomo, Diego (Coordinadores), Proceso Civil, Hacia una Nueva Justicia Civil (Editorial Jurídica de Chile, 2007).

Oberhammer, P., "Speeding up civil litigation in Austria: past and present instruments", en The Law's Delay: Essay on Undue delay civil in litigation, VAN RHEE, C.H. (editor) (Antwerpen, Intersentia, 2004). 
Oldham, James, "Truth-Telling in the Eighteenth-Century English Courtroom", en Law and History Review 12 (1994).

"Informal Lawmaking in England by the Twelve Judges in the Late Eighteenth and Early Nineteenth Centuries", en Law and History Review February 2011, Vol. 29, No 1.

Otson, Trisha, "The Passing Of The Ordeals And The Rise Of The Jury Trial", en Syracuse Law Review 109, 2000, p. 21.

PAGE, Wesley P., "Dead man talking: a historical analysis of west virginia's dead man's statute and a recommendation for reform", en West Virginia Law Review 109 (2007).

Palacios, Joaquín, Instituciones del Derecho Civil de Castilla, que escribieron los doctores Aso y Manuel (7a edición, Madrid, 1806) II.

PalomoVélez, Diego, "Las Marcas del Proceso Oral y Escrito diseñado en el Proyecto de Nuevo CPC Chileno", en Revista Chilena de Derecho, 36 (2009) 3.

, "La Prueba en el Proceso Civil Chileno. ¿Una actividad asumida con suficiente seriedad?", en De la Oliva, Andrés y Palomo, Diego (Coordinadores), Proceso Civil, Hacia una Nueva Justicia Civil (Editorial Jurídica de Chile, 2007).

Pérez Ragone, Alvaro; Palomo Vélez, Diego, "Oralidad y prueba: comparación y análisis crítico de las experiencias reformadoras del proceso civil en Alemania y España", en Revista de Derecho PUCV 32 (2009).

PothiER, Robert Joseph, Tratado de las Obligaciones (Barcelona, 1839) I.

PowelL, Edmund, The Principles and Practice of the Law ( $3^{\text {a }}$ edición, London, Hodges, Foster and Co; Grafton Street. Dublin, 1869).

RaZNOVICH, Leonardo, "Los principios generales del derecho probatorio y el proceso civil", en Revista IberoAmericana de derecho procesal 9 (2006).

Rioseco Enríquez, Emilio, La Prueba ante la Jurisprudencia. Derecho Civil y Procesal Civil. Confesión de Parte ( $1^{\text {a }}$ edición, Editorial Jurídica de Chile, 1998).

RodríGuez PaPIC, Ignacio, Procedimiento Civil. Juicio Ordinario de Mayor Cuantía (5ª edición, Santiago, Editorial Jurídica de Chile, 1995).

Sentis Melendo, Santiago, La prueba. Los grandes temas de derecho probatorio ( $1^{\text {a }}$ edición, Buenos Aires, Ediciones Jurídicas Europa-América, 1979).

SıIva, Rodrigo, Manual de Tribunales de Familia ( $1^{\text {a }}$ edición, Santiago, Editorial Jurídica Colección de Manuales Jurídicos, 2005).

SMITH, Tom, "Zealous Advocates: The Historical Foundations of the Adversarial Criminal Defence Lawyer", en Law, Crime And History, 2012.

SteIN, Alex, Foundations of Evidence Law (New York, Oxford University Press, 2008). 
TARUFFO, Michele, La prueba de los hechos (Madrid, 2005).

Van Rhee, C.H., "Evolución del Derecho procesal en Europa: Cómo el juez activo se convirtió en lo normal", en Revista Chilena de Derecho y Ciencia Política, Vol. 2, № 2, 2011.

Van Rhee, C.H., "The Development of Civil Procedural Law in Twentieth-Century Europe: From party Autonomy to Judicial Case Management and Efficiency", en C.H. van Rhee (ed.), Judicial Case Management and Efficiency in Civil Litigation, Antwerpen, 2008.

Verlanga Huerta, F. y Muñiz Miranda, J., Concordancias entre el Código Civil francés y los Códigos Civiles Estrangeros. Segunda edición (Madrid, 1847).

VERKERK, Remme, Fact-finding in civil litigation. A comparative perspective ( $1^{\text {a }}$ edición, Portland, Intersentia, 2010).

Wigmore, John Henry, A Treatise on the Anglo-American of Evidence in Trials at Common Law including the and Judicial Decisions of All Jurisdictions of the States and Canada (2 $2^{\mathrm{a}}$ edición, Boston, Little, Brown, and Co., 1923).

\section{Fuentes digitales}

Biblioteca del Congreso Nacional www.bcn.cl

Boletín Oficial del Estado www.boe.es

Cumbre Judicial IberoAmericana. www.cumbrejudicial.org

Unidroit. www.unidroit.org

Ministerio de Justicia de Chile. www.minjusticia.cl

Solon Online Journal Http://Www.Pbs.Plymouth.Ac.Uk/Solon/Hjournal2012vol1.Html

Westlaw. 81 S.Ct. 756.

www.jstor.org/stable/3302863 Competency of Witnesses, en The American Law

Register 10 (1852-1891), 5, New Series, volume 1 (1862)

www.heinonline.com

http://www.ssrn.com/

www.jstor.org 
